OPEN ACCESS

Edited by:

Paul Jurasz,

University of Alberta, Canada

Reviewed by:

Teresa Padro,

Sant Pau Institute for Biomedical

Research, Spain

Matthew Dean Linden,

University of

Western Australia, Australia

*Correspondence:

Christoph E. Hagemeyer christoph.hagemeyer@monash.edu

Specialty section: This article was submitted to Atherosclerosis and Vascular Medicine,

a section of the journal Frontiers in Cardiovascular Medicine

Received: 05 June 2019 Accepted: 03 September 2019 Published: 20 September 2019

Citation:

Rana A, Westein E, Niego $B$ and Hagemeyer CE (2019)

Shear-Dependent Platelet Aggregation: Mechanisms and

Therapeutic Opportunities. Front. Cardiovasc. Med. 6:141 doi: 10.3389/fCvm.2019.00141

\section{Shear-Dependent Platelet Aggregation: Mechanisms and Therapeutic Opportunities}

\author{
Akshita Rana, Erik Westein, Be'eri Niego and Christoph E. Hagemeyer* \\ Nanobiotechnology Laboratory, Australian Centre for Blood Diseases, Central Clinical School, Monash University, Melbourne,
} VIC, Australia

Cardiovascular diseases (CVD) are the number one cause of morbidity and death worldwide. As estimated by the $\mathrm{WHO}$, the global death rate from CVD is $31 \%$ wherein, a staggering $85 \%$ results from stroke and myocardial infarction. Platelets, one of the key components of thrombi, have been well-investigated over decades for their pivotal role in thrombus development in healthy as well as diseased blood vessels. In hemostasis, when a vascular injury occurs, circulating platelets are arrested at the site of damage, where they are activated and aggregate to form hemostatic thrombi, thus preventing further bleeding. However, in thrombosis, pathological activation of platelets occurs, leading to uncontrolled growth of a thrombus, which in turn can occlude the blood vessel or embolize, causing downstream ischemic events. The molecular processes causing pathological thrombus development are in large similar to the processes controlling physiological thrombus formation. The biggest challenge of anti-thrombotics and anti-platelet therapeutics has been to decouple the pathological platelet response from the physiological one. Currently, marketed anti-platelet drugs are associated with major bleeding complications for this exact reason; they are not effective in targeting pathological thrombi without interfering with normal hemostasis. Recent studies have emphasized the importance of shear forces generated from blood flow, that primarily drive platelet activation and aggregation in thrombosis. Local shear stresses in obstructed blood vessels can be higher by up to two orders of magnitude as compared to healthy vessels. Leveraging abnormal shear forces in the thrombus microenvironment may allow to differentiate between thrombosis and hemostasis and develop shear-selective anti-platelet therapies. In this review, we discuss the influence of shear forces on thrombosis and the underlying mechanisms of shear-induced platelet activation. Later, we summarize the therapeutic approaches to target shear-sensitive platelet activation and pathological thrombus growth, with a particular focus on the shear-sensitive protein von Willebrand Factor (VWF). Inhibition of shear-specific platelet aggregation and targeted drug delivery may prove to be much safer and efficacious approaches over current state-of-the-art antithrombotic drugs in the treatment of cardiovascular diseases.

Keywords: platelets, shear, aggregation, thrombosis, VWF 


\section{INTRODUCTION}

Since Bizzozero first identified the remarkable contribution of platelets in both hemostasis and thrombosis (1), substantial progress has been made in understanding, diagnosing and treating several platelet-related disorders. With technological advances in platelet research, immense insights were generated into the mechanisms underlying "hemostatic" and "thrombotic" activities of these intriguing blood cells.

Platelets, or thrombocytes (2-4 $\mu \mathrm{m}$ in greatest diameter), are anucleate cells produced by megakaryocytes, that circulate in the human bloodstream for 7-10 days before being eliminated by the liver and spleen $(2,3)$. Primarily, platelets sense and respond to vascular injury by preventing blood loss following vessel damage and tissue trauma. But in addition to this essential hemostatic function, platelets also play a key pathological role in cardiovascular diseases.

Several decades of research into platelets and their varying pro-thrombotic roles at sites of vascular injury have established the synergistic interplay between two distinct, yet complimentary systems in the platelet activation process, being (i) biochemical factors (adhesive molecules and extra-cellular matrix proteins, as well as soluble agonists) and (ii) biomechanical factors, such as hemodynamic shear forces $(4,5)$.

While the biochemical factors mediating clot formation have been extensively investigated, the vital role of the local fluid mechanical microenvironment that facilitates platelet-ligand interactions, thus regulating the release of biochemical cues, must not be overlooked in the development process of effective anti-thrombotic strategies. In particular, the mechano-sensitive plasma protein von Willebrand factor (VWF) and its binding with platelet receptor glycoprotein Ib $\alpha(\mathrm{GPIb} \alpha)$ play a crucial role in hemostasis, yet is also key to pathological thrombus initiation and propagation. Here, we discuss the mechanosensitive interaction of VWF with GPIb $\alpha$, its dependency on shear forces generated by blood flow and possible therapeutic approaches exploiting this protein axis. Furthermore, novel shear-sensitive drug delivery platforms, designed to specifically target occluded vessels, are also discussed in this review.

\section{THE TRADITIONAL, BIOCHEMICAL CASCADE OF THROMBOSIS}

Upon vascular injury, platelets adhere to exposed sub-endothelial matrix proteins, mainly VWF and collagen, followed by their activation, aggregation and finally formation of a "platelet plug" at the injury site. Under normal physiological conditions, the pro-thrombotic hemostatic response is neutralized by counter anti-thrombotic and anti-coagulatory mechanisms that confine the clot formation specifically to the injury site. However, at diseased vascular sites (such as atherosclerotic lesions) this balance is disrupted due to the highly thrombogenic contents and the stenotic geometry of the lesions, which cause an increase in local shear rates. The exacerbated biochemical and biomechanical responses combined can lead to abnormal thrombus propagation, turning a life-saving defense mechanism into a life threatening one.

In the traditional concept of platelet aggregation, solubleagonists such as ADP and thromboxane A2 (TxA2) were assumed to play the central role in driving thrombus development. As per this model, the process of thrombogenesis and propagation comprised of three sequential steps, including platelets adhesion, activation, and subsequent aggregation at the site of vascular injury.

\section{Platelet Adhesion}

The initial arrest of platelets at the site of vascular damage is primarily facilitated by shear-dependent interaction of platelet receptor GPIb $\alpha$ with the A1 domain of VWF $(6,7)$. The GPIb $\alpha$ A1 binding is also key for platelet aggregation during thrombosis, which will be discussed in detail later. Other transmembrane platelet receptors mediating platelet adhesion include GPVI (8) and integrin $\alpha_{2} \beta_{1}$ (9), that bind directly to collagen (10).

\section{Platelet Activation}

The adhesion of platelets to sub-endothelial matrix proteins leads to platelet intracellular signaling, which activates the cell. Briefly, platelet activation results in conformational change (from the typical discoid shape to an elongated form) (11) and degranulation (i.e., release of the platelet cytoplasmic granules content) (12). $\alpha$-granules release VWF and coagulation factors, such as fibrinogen, factor V, factor XIII, and P-selectin (also expressed on the platelet surface following activation); Dense granules release platelets agonists, such as serotonin and adenosine diphosphate (ADP) (13). This process results in sustained, oscillatory cytosolic $\mathrm{Ca}^{2+}$ flux, production of $\mathrm{TxA}_{2}$, exposure of phosphatidylserine (PS), expression of P-selectin, and microvesiculation, allowing coagulation factors to bind the activated platelet. The activation step also involves additional platelet recruitment via an outside-in signaling, induced by a paracrine action of the soluble agonists released from activated platelets themselves (e.g., ADP, $\mathrm{TxA}_{2}$ ) or by activated coagulation factors, such as thrombin. While the purinergic receptor $\mathrm{P}_{2} \mathrm{Y}_{12}$ is the platelet receptor for ADP, protease-activated receptors (PAR) 1 and 4 bind and potently react to thrombin $(12,14,15)$.

\section{Platelet Aggregation}

Following platelet adhesion and activation, the integrin $\alpha_{\mathrm{IIb}} \beta_{3}$ (also known as GPIIb/IIIa) undergoes conformational change through inside-out signaling and binds fibrinogen $(16,17)$. This receptor-ligand interaction results in the formation of platelet aggregates, ultimately forming a platelet plug that can prevent bleeding in case of minor injuries. However, for a damage of a greater magnitude, primary hemostasis is followed by secondary hemostasis, in which fibrin production stabilizes the clot to prevent hemorrhage (18). Since only initially-adhered platelets are in direct contact with thrombogenic surfaces, postactivation signals originating from platelets themselves as well as soluble agonists play a central role in triggering ongoing thrombus growth.

It has long been established that thrombus formation occurs via an interplay between two distinct, yet complementary 
platelet aggregation mechanisms: soluble agonist-dependent (biochemical) and rheology-dependent (biomechanical) pathways. However, major anti-thrombotic drugs target the biochemical axis of platelet aggregation without considering the biomechanical aspect. As a result, current anti-platelet drugs not only have limited clinical efficacy in treating cardiovascular diseases, but also carry significant side effects, that can be lifethreatening at times. Thus, there is a pressing need to develop novel drugs that target growing thrombi specifically under pathological shear forces.

\section{Limitations of Current Anti-platelet Drugs}

Anti-platelet drugs have proven to be the keystone of antithrombotic therapy, as demonstrated by multiple, large-scale clinical trials and meta-analyses (19, 20). Despite being a mainstay in preventing atypical platelet activation/aggregation in cardiovascular events, anti-platelet drugs face several limitations in the clinical settings. These include heterogeneity in interpatient response with considerable drug resistance (21-24), delayed onset of action $(25,26)$, low safety profile $(27,28)$ and systemic administration nature, resulting in limited effective concentration at the site of interest $(29,30)$. However, the most crucial side effect of antiplatelet drugs is a bleeding risk, that can have serious implications for the patient, including death (31-34). Conventional anti-platelet drugs blocking GPIIb/IIIa (abciximab, eptifibatide, tirofiban) or targeting $\mathrm{TxA}_{2}$ (dazoxiben, ifetroban, dipyridamole) and ADP-P2 $\mathrm{Y}_{12}$ pathways (ticagrelor, cangrelor) have been associated with enhanced hemorrhagic episodes due to undesired impairment of hemostasis in addition to the desired prevention of arterial thrombosis $(35,36)$. Further, prolonged use of some cyclooxygenase-2 (COX-2) inhibitors, such as valdecoxib, parecoxib, and celecoxib, has been found to increase the recurrence of serious cardiovascular events in patients $(37,38)$.

\section{Dual Antiplatelet Therapy and Triple Therapy}

The Clopidogrel in Unstable Angina to Prevent Recurrent Events (CURE) trial demonstrated the advantages of dual antiplatelet therapy (DAPT), including aspirin and $\mathrm{P}_{2} \mathrm{Y}_{12}$ receptor antagonist (clopidogrel, prasugrel, or ticagrelor) in acute coronary syndrome (ACS) patients over aspirin monotherapy $(39,40)$. Despite vast evidence supporting the usage of DAPT over aspirin alone in ACS or post-percutaneous coronary intervention (PCI), clinicians have not reached a consensus on the optimum duration of the therapy in these patients (41). Shortterm DAPT is typically less effective in attenuating thrombotic events, but has lower bleeding risk. In contrast, long-term DAPT may reduce ischemic risk but increase the occurrence of major bleeding events, with a higher all-cause mortality rate $(42,43)$.

Triple therapy, including aspirin, $\mathrm{P}_{2} \mathrm{Y}_{12}$ antagonist and oral anticoagulant has shown a 3 -fold increase in bleeding events, as compared to oral anticoagulant alone $(44,45)$. Generally, intensification of antithrombotic regimens for a maximal clinical benefit in a broader patient population comes at a major cost of significant bleeding events that may be proven fatal at times. Refining the anti-thrombotic effects of a drug without exacerbating the bleeding risks remains a major challenge to date.

In conclusion, current antiplatelet therapeutics are unable to meet the major clinical need to selectively prevent pathological thrombosis without interfering with the physiological process of hemostasis. As mentioned above, one of the significant distinctions between the two processes is the substantial difference in local shear rates, with exceedingly high shear levels observed in pathological thrombi at sites of vessel occlusion or atherosclerotic plaque rupture $(46,47)$. No existing, clinically-used antiplatelet drug is known to specifically respond to this biomechanical force at the site of pathological thrombus formation.

\section{BIOMECHANICAL ASPECT OF THROMBOSIS}

\section{Shear Forces Resulting From Blood Rheology}

Blood, circulating in the vessels via pressure differences, exerts forces on its components as well as the vascular walls (48). Blood flow is laminar, with maximal velocity at the vessel lumen center and zero at the vessel wall. The velocity of circulating blood changes differentially between its discrete fluid layers, thereby generating a tangential force (force acting along a tangent to the object) between them. This tangential force per unit area between laminae, termed "fluid shear stress" $(\zeta)$, is expressed in Pascal $(\mathrm{Pa})$. Alternatively, wall shear rate $\left(\gamma\right.$, expressed in $\left.\mathrm{s}^{-1}\right)$, defined as the rate of change in fluid velocity as a function of distance from the vessel wall, is used to describe hemostasis and thrombosis. In veins and larger arteries experiencing high shear rates, blood exhibits the characteristics of a Newtonian fluid, with the resulting wall shear stress directly proportional to the local shear rate (49).

The biomechanical forces generated by the virtue of blood flow play a vital role in uniting or separating the essential hematological components engaged in clot formation. Under normal hematocrit conditions ( $\sim 40 \%)$ (50), erythrocytes mainly circulate along the central axis of the blood vessel due to axial migration. Consequently, platelets travel in close proximity to the vessel walls, a phenomenon that facilitates their binding to adhesive ligands at the reactive endothelial layer in damaged vascular sites $(49,51-53)$.

Under physiological conditions, typical wall shear rates of $300-800 \mathrm{~s}^{-1}$ occur in the large arteries, $15-200 \mathrm{~s}^{-1}$ in veins and $450-1,600 \mathrm{~s}^{-1}$ in micro arterioles (54). However, vessel stenosis due to atherosclerotic lesions or pre-existing thrombi can increase shear rates well beyond $10,000 \mathrm{~s}^{-1}$ resulting in a localized pro-thrombotic microenvironment $(48,54,55)$.

\section{Platelet Adhesion and Tethering to VWF Under Shear Conditions}

The arrest of flowing platelets occurs on immobilized VWF via interactions between the A1 domain of VWF and the platelet receptor GPIb $\alpha$. These bonds have a rapid on-rate but short lifetimes, hence only supporting transient platelets adhesion and 
classical stop and go motion (56). Membrane tethers, consisting of smooth cylinders of lipid bilayer, then extend from the platelet surface and are pulled by shear forces. Membrane tethers are vital in prolonging platelet adhesion times, allowing for small platelet aggregates to form, which in turn maintain high local concentration of activating signals by eradicating any "washout effects" of soluble agonists by blood flow.

Tethers act as adhesion contacts between platelets and platelet-matrix, and subsequently facilitate bonding between the $\alpha_{\text {IIb }} \beta_{3}$ platelet receptors and the Arg-Gly-Asp (RGD) motif of the VWF $\mathrm{C} 1$ domain (57). In normal physiology, under lowshear regimes (600-900 $\left.\mathrm{s}^{-1}\right)$, the aggregation is dominated by $\alpha_{\text {IIb }} \beta_{3}$-dependent interactions, while under intermediate shear rates $(1,000$ to $10,000 \mathrm{~s}-1)$ both GPIb $\alpha$ and $\alpha_{\text {IIb }} \beta_{3}$ play an important role in platelet aggregation. However, VWFdependent interactions become increasingly dominating as shear rates increase $\left(>10,000 \mathrm{~s}^{-1}\right)(4,58,59)$. Consequently, VWF and GPIb $\alpha$ play a vital role in hemostasis but an even more pivotal role in the onset of thrombosis, thus contributing in several diseases.

\section{VWF Structure, Native Confirmation, and Pathophysiological Significance}

Von Willebrand Factor is a large, blood-borne multimeric glycoprotein, crucial for hemostasis and thrombosis. It is secreted by both endothelial cells (where it is stored in Weibel-Palade bodies) and megakaryocytes (that also pack VWF in $\alpha$-granules in platelets) as a globular multimer, consisting of identical subunits of $250 \mathrm{kDa}$, connected via disulfide bonds to form ultra-large VWF (ULVWF), weighing up to 20,000 kDa. Each subunit of ULVWF harbors multiple functional domains, each with a specific function. The major functionalities of plasma VWF are exhibited by three adjacent A domains, namely A1, $\mathrm{A} 2$, and $\mathrm{A} 3$. While $\mathrm{A} 1$ is primarily responsible for binding with the platelet receptor GPIb $\alpha, \mathrm{A} 3$ acts as the immobilization site for VWF on the collagen matrix $(60,61)$. A2 is responsible for size regulation of ULVWF in blood physiology, as described below. Under shear forces, self-association of plasma VWF occurs also on the surface of platelets (62) and endothelial cells (63), thereby creating fibrillar structures that further facilitate platelet adhesion. As mentioned earlier, VWF is physiologically and pathologically important protein. It is responsible for several hemorrhagic disorders, including von Willebrand disease (VWD) and Bernard Soulier syndrome. VWD is the most common, hereditary bleeding disorder, resulting from qualitative or quantitative deficiencies in VWF, presiding a diverse range of mild to severe hemorrhagic episodes. VWD can be categorized into three types: VWD type 1, a quantitative defect; VWD type 2, a qualitative defect and VWD type 3, the most severe defect characterized by complete absence of VWF. VWD type 2 can be further divided into four sub-types, including type 2A (dominant loss-of-function mutations), type 2B (dominant gain-of-function mutations), $2 \mathrm{M}$ (impaired binding to GPIb $\alpha$ ) and type $2 \mathrm{~N}$, or Normandy defect (impaired binding to factor VIII) (64). Moreover, acute coronary syndrome (ACS), acute myocardial infarction, stroke and ischemic events have been associated with increased levels of plasma VWF in several population-based studies $(65,66)$. Other studies have suggested that the single nucleotide polymorphisms (SNPs) on the gene coding for VWF may lead to coronary heart diseases in advanced atherosclerotic and diabetic patients $(67,68)$. Histopathological studies have also identified the pathogenic role of VWF in venous thromboembolism (VTE) by revealing VWF-rich thrombi in patients who died from the disease (69).

\section{Shear-Induced Activation and Conformational Change of VWF}

Following secretion from Weibel-Palade bodies in the endothelium, ULVWF multimers (several $100 \mu \mathrm{m}$ long) are inherently hyperactive as they carry numerous ligand binding sites and are more receptive to hemodynamic forces due to their size (70).

The shear force is comprised of rotational and elongational flow components (Figure 1A) $(71,72)$. Under low shear forces, VWF exists in "coiled" or globular conformation due to monomeric self-association (73). In this native conformation, binding sites in the A1 domain are believed to be buried and thus, inaccessible to platelets or other biomolecules (74, 75). Under flow-induced shear stress, VWF exhibits conformational variation, including end-over-end tumbling and periodic elongation and compaction $(76,77)$. Indeed, above a critical shear rate, the intrinsic interactions between the monomeric units are overcome by the hydrodynamic drag, resulting in stretching of VWF, thereby exposing the cryptic A1 epitopes $(77,78)$. While the critical shear rate to elongate surfaceimmobilized VWF is about $3,000 \mathrm{~s}^{-1}$, circulating plasma VWF requires $\sim 5,000 \mathrm{~s}^{-1}(79,80)$. Interestingly, the required force for VWF elongation increases with increasing shear rates (77).

At sites of vessel constriction, fluid acceleration and subsequent deceleration create local force gradients. As a result, VWF circulating nearby experiences an elongational pull in the direction of flow due to a faster-moving proximal end and a slower-moving distal end (Figure 1B). Importantly, studies have shown that the unfolding process of VWF can be achieved at significantly reduced flow rates if they produce a gradient of shear forces (i.e., when flow is accelerating or decelerating), compared to a flow with high, but constant shear rate $(81,82)$. The is because of the large size of VWF where the leading end of the molecule will experience a different strain rate compared to the trailing end, hence substantially lower forces are required to unfold the protein (76).

\section{Shear-Sensitive VWF A2 Domain and Mechanoenzymatic Cleavage}

ULVWF concatemers (long molecules containing multiple copies of the same protein sequence, linked end-to-end in series; Figure 3) remain tethered to the endothelial cell surface in stretched conformation with exposed A2 domain that completely unfolds due to missing long-range disulfide linkages, unlike A1 and A3 domains (84). On complete refolding of the A2 domain, a peptide bond, Tyr1605 -Met1606, located in the centrally situated $\beta 4$ sequence in the $\beta$-sheet (at the center of the folded 
A

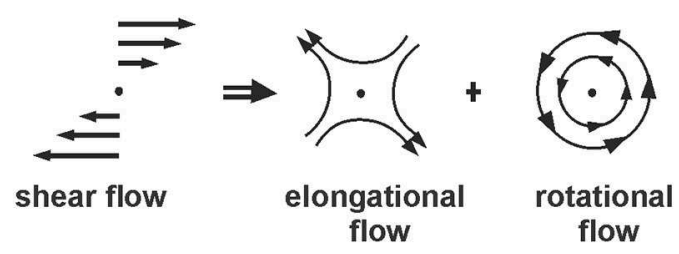

B
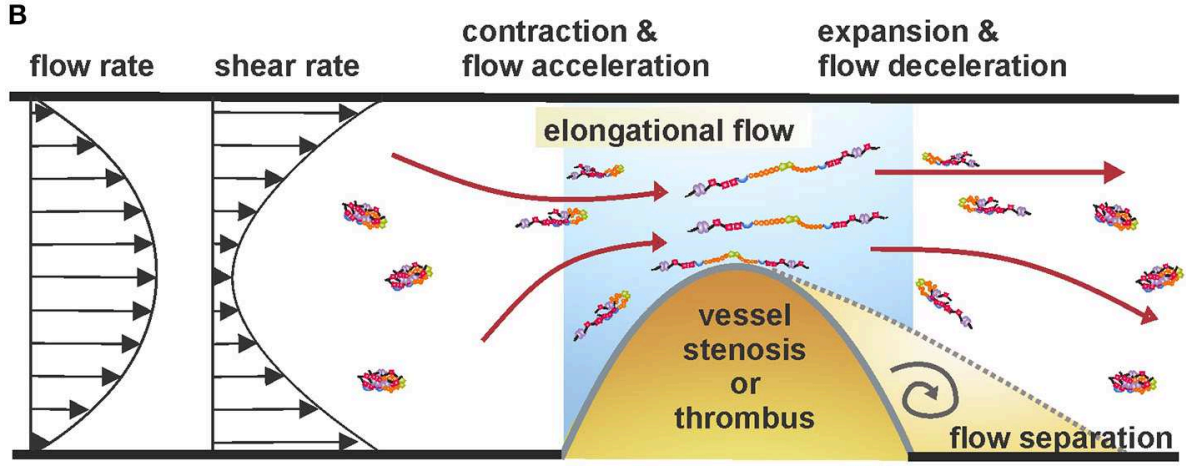

Folded VWF

\section{Unfolded VWF}

FIGURE 1 | (A) Shear flow, as a superimposition of rotational and elongational flow components (71, 72). (B) Unfolding of coiled WWF under elongational flow or shear rate gradients at sites of vessel stenosis.

A2 domain), is recognized by ADAMTS-13, a metalloprotease enzyme (81). ADAMTS-13 cleaves ULVWF at this scissile bond and releases the smaller and less hemostatically active VWF strings into the blood stream. This regulatory mechanism prevents VWF hyperactivation under physiological shear rates. Severe deficiency of ADAMTS-13 activity caused by inhibiting autoantibodies results in ultra-large multimers of VWF in blood. These ULVWF cause systemic microvascular thrombosis, ultimately leading to a blood disorder called thrombotic thrombocytopenic purpura (TTP) (85). Single molecule studies found that proteolysis of VWF is regulated by a $\mathrm{Ca}^{2+}$ binding $\alpha 3-\beta 4$ loop in the A2 domain. Therefore, within the physiological calcium concentration range the refolding kinetics of A2 can increase five times without affecting the unfolding event (86).

\section{Shear-Sensitive VWF A1 Domain and Platelet Arrest}

The VWF A1 domain plays a remarkable role in initiating thrombus formation under pathological shear rates. Under low shear conditions or absence of any exogenous VWF modulators, such as ristocetin and botrocetin, no interaction occurs between VWF and platelet surface receptors. However, above threshold shear levels ( $800 \mathrm{~s}^{-1}$ in humans), the exposed A1 domain of unfolded VWF-immobilized onto exposed collagen-binds GPIb $\alpha$ receptors in (GP)Ib-IX complex on platelets cruising within the "latching distance" of the vascular wall, thus initiating platelet adhesion to VWF and aggregate formation $(57,59,87-89)$.
A1 domain is the most positively charged domain of VWF due to the presence of Cys509-Cys695 disulfide bond, a major positively charged region surrounded by two discontinuous anion flanking sequences, which contains seven sialylated glycosylation sites (74). Studies using artificial peptides indicated that residues Asp514-Glu542 within this disulphide loop in the A1 domain could be involved in GPIb $\alpha$ binding (90). Ristocetin, an antibiotic from Nocardia lurida, activates VWF and facilitates A1-GPIb $\alpha$ interaction in a similar fashion as elevated shear. Ristocetin binds to proline-rich sequence, Glu700 to Asp709 and the C-terminal to the Cys509-Cys695 disulphide bond in the A1 domain. In some studies, anti-VWF A1 (5D2, CR1, and 6G1) and anti-GPIb $\alpha$ monoclonal antibodies (AK2 and AN51), mapping ristocetin-bound A1 and GPIb $\alpha$ epitopes, selectively inhibited both ristocetin-induced and shear-induced platelet aggregation $(74,91)$.

Finally, the A1 domain also acts as the main binding site to non-fibrillar collagen type VI (92). Like the A3 domain, which serves as the main binding site for collagens I and III, the A1 domain can bind both types, although with less propensity. In fact, under high shear forces, the unraveled A1 domain can act as surrogate for the A3 domain in recruiting platelets to collagen.

\section{Force-Induced A1 Activation}

Recent study described a two-step conformational transformation mechanism of A1 activation after VWF senses mechanical force (83). The first step involves elongation of VWF, immobilized to the vessel wall, from a globular form to a stretched form, followed by a tension-dependent local transition 


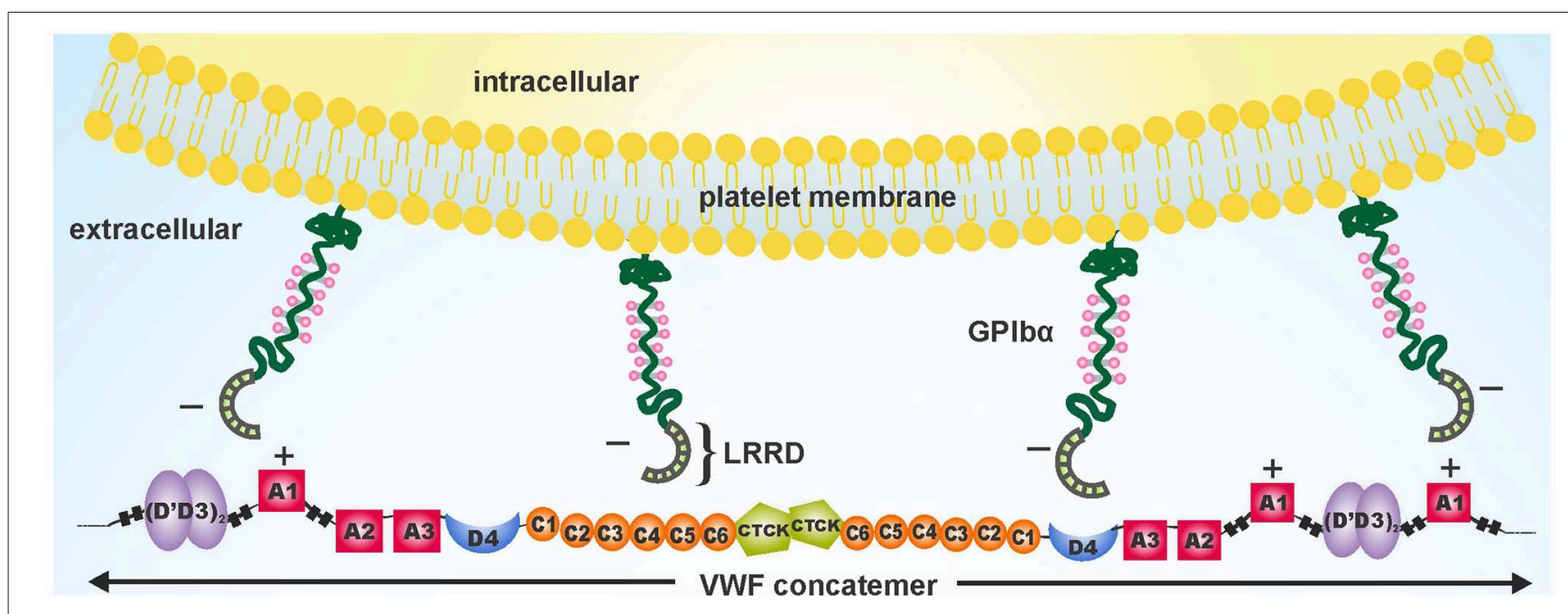

FIGURE 2 | Schematic depiction of the electrostatic complementary interactions between negatively charged platelet surface receptors GPIba and positively charged A1 domains exposed on fully unfolded WWF. Adapted and modified from Fu et al. (83).
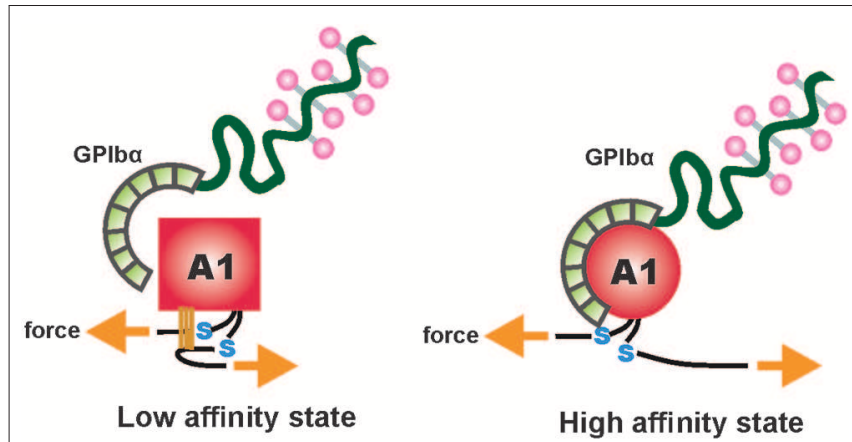

FIGURE 3 | A two-state model depicting flow-induced activation of the A1 domain of WWF, tethered to the vessel wall. Hydrogen bonds between residues, internal and external to the $\mathrm{A} 1$ disulfide link are disrupted due to mechanical tension under shear flow. This results in conversion of the A1 domain from a low-affinity, flexed state to a high-affinity extended state. Adapted and modified from Fu et al. (83).

to a high affinity state. Elongation results in breaking of weaker hydrogen bonds between distal monomers in the tethered VWF concatemer. The molecule then experiences a tensile force upstream, along the backbone toward the tether point. This exposes an almost linear array of A1 domains that become easily accessible to platelets. When this tensile strength reaches $\sim 21$ piconewton $(\mathrm{pN})$ in the upstream regions, $\mathrm{A} 1$ transforms into a second state exhibiting high affinity for GPIb $\alpha$, that depends upon electrostatic interactions [Figure 2; (83)].

\section{Platelet GPIb $\alpha$ and A1 Binding}

At the onset of hemostasis and thrombosis, platelets tether or translocate onto the VWF substrate immobilized on the damaged vessel site. The initial contact between circulating platelets and VWF is made via binding interactions between the A1 domain of VWF and the $\mathrm{N}$ terminal domain of GPIb $\alpha$ receptor $(56,57)$. In physiology, the levels of ligand-receptor interactions are regulated, as insufficient interactions may affect hemostasis by causing bleeding while excessive interactions may lead to thrombosis.

\section{GPIb $\alpha$ Receptor}

GPIb-IX-V receptor complex is abundantly expressed with about 25,000 copies of GPIb-IX complex and 12,000 GPV copies on resting platelets, making it suitable for platelet adhesion and aggregation (93). The complex consists of GPIb $\alpha$, GPIb $\beta$, GPIX, and GPV sub-units in the stoichiometric ratio of 2:4:2:1 (94). GPIb complex comprises of GPIb $\alpha$ and GPIb $\beta$, connected via disulfide bond that tightly link with GPIX to form GPIbIX complex. GPV does not participate in VWF binding or signaling (95). GPIb $\alpha$ consists of a N-terminal leucine-rich repeat domain, a macro glycopeptide region followed by a long stalk, a C-terminal transmembrane helix and a short cytoplasmic domain (96). Polymorphisms in GPIb $\alpha$ have been linked with a greater risk of cardiovascular manifestations, such as stroke and myocardial infarction in young individuals $(97,98)$.

\section{GPIb $\alpha$-VWF A1 Binding Kinetics}

Crystal structures of the VWF A1-GPIb $\alpha$ complex, both of wild-type or a gain-of-function $\mathrm{A} 1$ and $\mathrm{GPIb} \alpha$ mutations, exhibited two distinct binding interfaces (99). The leucine rich repeat domain (LRRD) of GPIb $\alpha$ [basal isoelectric point (pI): 5.87] is a negatively charged, concave- or horseshoe-shaped region, that binds with the positively charged VWF A1 domain (basal pI: 9.4) via electrostatic interactions [Figure 3; (99)]. The electrostatic complementarity of the binding interfaces enhances the association rate of A1-GPIb $\alpha$ complex (100).

Shear flow modulates the dissociation rates of the A1-GPIb $\alpha$ bond. Earlier studies hypothesized that at forces $<22 \mathrm{pN}, \mathrm{A} 1-$ GPIb $\alpha$ exhibits a "catch" bond behavior, in which bond lifetime prolongs as shear forces increase (translating as tensile forces). 
Above $22 \mathrm{pN}$, the bond acts as a "slip" bond, where increasing shear results in shortened bond lifetime $(101,102)$.

Later studies using Receptor and Ligand In a Single Molecule (ReaLISM) constructs described the A1-GPIb $\alpha$ bond as a mechanically stabilized "flex bond." The bond exists in two "slip" bond states, one flexed, low-affinity state associated with lower force and the other extended, high-affinity state engaging $\sim 10 \mathrm{pN}$ with around 20-fold longer bond lifetime and greater ability to withstand strong hemodynamic forces (103). Tensile force stabilizes the high-affinity state, thus strengthening the bond under pathological shear rates. Similar phenomenon was observed for ristocetin, a VWF modulator that alters the conformational state of the A1-GPIb $\alpha$ bond in a shearedlike configuration. Both ristocetin and tensile force selectively stabilize the extended state, corresponding to shear-induced state $(74,91,103)$. Formation of mechanically stabilized flexbonds may account for the resistance of A1-GPIb $\alpha$ complex under extreme pathological shear rates, resulting in platelet adhesion and activation-independent platelet aggregation at these extreme shear conditions (80). Interestingly, the VWF A1 domain with type $2 \mathrm{~B}$ mutations forms "slip" bonds with platelet GPIb $\alpha$, resulting in prolonged bond duration even at low shear rates (101).

\section{GPIb $\alpha$ Mechanosensing and Mechanotransduction}

Recent findings employing biomechanical techniques at the single molecule level have provided insight into how platelets mechanosense shear forces and subsequently convert these mechanical cues into biochemical signals to promote thrombus growth and stability. A structured, quasi-stable MechanoSensitive Domain (MSD), consisting of around 60 residues, was identified in the juxtamembrane stalk region of GPIb $\alpha$ (104). VWF A1-mediated mechanical pulling on the GPIb $\alpha$ N-terminal domain results in unfolding of the MSD in GPIb-IX complex. Furthermore, this shear-mediated pulling of tethered platelet onto immobilized VWF generates tensile force along GPIb $\alpha$ that not only unfolds the relatively unstable MSD, but also lowers the overall force applied on A1-GPIb $\alpha$ complex, in turn stabilizing the tethering of platelet. MSD unfolding occurs at similar force range $(5-20 \mathrm{pN})$ as that required for the A1-GPIb $\alpha$ complex to transition into high-affinity flex-bond state (101, 103). Due to direct contact of the MSD with GPIb $\beta$ and GPIX subunits, unfolding of the mechanosensitive domain may induce conformational changes in these subunits, thereby facilitating intracellular signal transmission (104).

In mutational studies with human/canine chimeras of GPIb $\alpha$, co-crystal structure of the A1-GPIb $\alpha$ complex showed minimal contact between the predominantly negatively charged LRR2-4 (Leu60-Glu128) sequence and VWF A1 under static conditions. Interestingly however, this sequence was not only important for ristocetin-induced binding but also increasingly fundamental for platelet adhesion at increasing shear rates. This finding further supports the idea of force-mediated transition from low to a stabilized, high-affinity state of ligand-receptor flex-bond wherein, the LRR2-4 of GPIb $\alpha$ establishes tight contact with the A1 domain $(105,106)$. Yet, the conformational dynamics of the LRRD and its role in signal transduction within platelets is not well-understood.

Recently, using molecular dynamic simulations and biomembrane force probe, unfolding of LRRs in the $\mathrm{N}$ terminal domain of GPIb $\alpha$ was observed under force application, initiating at LRR2-4 and propagating to neighboring LRR sequences. LRR folding prolongs the A1-GPIb $\alpha$ bond lifetime by increasing the force required for its disconnection from 10 to 25 pN (i.e., a "catch" bond behavior) and reduces the bond lifetime thereafter (a "slip" bond behavior) as described earlier in section GPIb $\alpha$-VWF A1 Binding Kinetics $(101,107)$.

Thus, far, the GPIb $\alpha$ mechanosensing was recapitulated by the conformational dynamics of MSD and LRRD. However, mechano-transduction or how the mechanical cues were transformed into biochemical signals remained elusive. Ju et. al. demonstrated that mechanotransduction of force into signals was done by cooperative interplay between the mechanosensing domains MSD and LRRD (108). The study showed that unfolding of LRRD enhances the unfolding of MSD by force transmission through mucin-like macroglycopeptide located between the two domains. MSD unfolding event may aid further unfolding of LRRD, thus prolonging the A1-GPIb $\alpha$ bond lifetime. This cooperativity pattern between the mechanoreceptor domains is maximal around the optimal force of $25 \mathrm{pN}$ [108].

Single platelet calcium imaging identified three types of $\mathrm{Ca}^{2+}$ fluxes: Null-type, baseline with background noise; $\alpha$-type, latent phase following a high spike with a rapid decay; and $\beta$-type, being fluctuating or slowly increasing $\mathrm{Ca}^{2+}$ signals to an intermediate level followed by slow decay to the baseline. GPIb $\alpha$-A1 binding results in transient $\alpha$-type $\mathrm{Ca}^{2+}$ flux, promoting reversible arrest of translocating platelets on immobilized VWF $(92,109)$. Timelapse correction analysis revealed that while LRRD unfolding enhances the $\mathrm{Ca}^{2+}$ flux, MSD unfolding event was essential to generate $\alpha$-type $\mathrm{Ca}^{2+}$ signal. In resting platelets, a signaling molecule-14-3-3 3 -is bound to both GPIb $\alpha$ and GPIb $\beta$ (110). Upon A1-GPIb $\alpha$ binding, the head domain of GPIb $\beta$ binds with the unfolded MSD while detaching its cytoplasmic tail

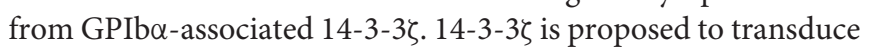
the mechanical signal of MSD unfolding into intracellular biochemical signaling across the platelet membrane. This leads to the downstream activation of adapter molecules, ultimately resulting in cytoplasmic calcium flux [108]. In addition, GPIb $\alpha-$ A1 interactions lead to other intracellular signaling events, including integrin $\alpha_{\mathrm{IIb}} \beta_{3}$ activation, ADP, thrombin and TxA2 production and P13K activation.

\section{Integrin $\alpha_{\text {IIb }} \beta_{3}$ (GPIIb/IIla) Activation}

GPIb $\alpha$ mechano-signaling results in a transient calcium flux that thrusts the majority of integrins to an intermediate activation state. This intermediate state subsequently facilitates the outsidein signaling of $\alpha_{\mathrm{IIb}} \beta_{3}$ integrins for further transformation into an active state. These intermediate and active integrin states have longer bond lifetimes and higher ligand affinity that stabilize the platelet aggregates (111). The high-affinity state of integrin $\alpha_{\mathrm{IIb}} \beta_{3}$ enables its binding with fibrinogen and VWF to strengthen the adhesive bonds among platelets and stabilize aggregation. 


\section{Shear Dependent Platelet Aggregation: Evolving Concepts From Constant Shear to Gradients of Shear}

Distinct aggregation mechanisms operate based on different shear ranges $(5,112) . \alpha_{\mathrm{II}} \beta_{3}$-fibrinogen-dominated platelet aggregation occurs mainly under low shear rates $\left(<1,000 \mathrm{~s}^{-1}\right)$ in veins and larger arteries, with soluble agonists maintaining the activated state of integrins, thus stabilizing the bonds. Plateletplatelet interactions become increasingly dependent on VWF and its binding with both $\alpha_{\mathrm{IIb}} \beta_{3}$ and GPIb $\alpha$ receptors at increasing shear range $\left(1,000-10,000 \mathrm{~s}^{-1}\right)$, as observed in moderate arterial stenosis and arterioles. Notably, at pathological shear rates $\left(>10,000 \mathrm{~s}^{-1}\right)$, resulting from acute vessel constriction, initial aggregation exclusively relies upon VWF-GPIb $\alpha$ bonding, without the prerequisite of platelet activation or $\alpha_{\mathrm{IIb}} \beta_{3}$ interaction $(5,80)$. Above this shear threshold, soluble VWF binds with GPIb $\alpha$ receptors on adherent platelets, resulting in dominating platelet-platelet interactions that induce "large rolling aggregates" onto immobilized VWF. Enhanced interplatelet interactions mediated by soluble VWF result in a growing transient aggregate under extreme shear conditions (80). A dramatic increase in shear may also destabilize vulnerable thrombi formed post-plaque rupture, generating emboli that can flow to distal organs, causing partial or complete vessel blockage downstream of plaque origin (113).

The mechanisms of platelet aggregation described up until this point operate under simplified laminar shear conditions, with constant shear and no turbulence in consideration. However, in pathology, blood rheology can alter dramatically, both spatially and temporally, in the local microenvironments generated by vascular lesions, acute stenosis or pre-existing thrombi. Thrombus propagation within the blood vessel is a complex and dynamic process that can incur flow perturbations, resulting in vortex and eddy formation, shear gradients, recirculation zones, flow separation and reciprocation $(114,115)$. These disturbed flow parameters have substantially stronger prothrombotic effects as compared to constant shear flows of the same magnitude.

\section{Platelet Aggregation Mechanisms Under Complex Shear Gradient: Novel Concepts}

Elegant studies both in vitro and in vivo have emphasized the indispensable role of shear gradient-dependent functionality of VWF in recruiting platelets for thrombus propagation. As mentioned above, thrombus development under high shear conditions is an intricate process that is principally driven by hemodynamic forces. Vessel stenosis can create a microenvironment wherein the forces experienced by blood components vary vastly as compared to any other non-obstructed sections of the vasculature.

Pathological shear rates briefly exceeding 10,000 $\mathrm{s}^{-1}$ can be generated locally by occlusive thrombi at the sites of atherosclerotic plaque ruptures, causing an exaggerated aggregation response by platelets, thus precipitating myocardial infraction or ischemic stroke $(24,116)$. A landmark study by Nesbitt et al. (117) elucidated the principle role of shear microgradients, resulting from vascular constriction, in promoting stabilized, discoid platelet aggregation and thrombus progression post-stenosis. Shear gradient regions consist of three zones: a shear acceleration zone at the proximal end of stenosis, a peak shear zone at the apex of stenosis and a shear deceleration zone at the distal end of stenosis. While the high shear region enhances platelet activation $(118,119)$, the low shear region post stenosis provides sufficient time and conducive flow conditions for platelet hyper-aggregation and thrombus progression [Figure 4; (121-123)]. Computational Fluid Dynamics (CFD) modeling of stenosed vessels showed that for an input shear rate of $1,800 \mathrm{~s}^{-1}$ upstream of the stenosis, a shear rate $20,000 \mathrm{~s}^{-1}$ is generated at the apex with rapid deceleration to about $800 \mathrm{~s}^{-1}$ post-stenosis, inducing exacerbated platelet aggregation. Interestingly, no thrombus has developed under similar conditions with a constant high shear rate of 20,000 $\mathrm{s}^{-1}$ (117). As it turns out, platelets experiencing sudden and steep shear acceleration form transient aggregates without prior activation or shape change, by tethering onto immobilized VWF with the boost of soluble VWF. Labile interactions between VWF and GPIb $\alpha$ result in rapid translocation of platelets into downstream region with much lower shear rates. Marked reduction in shear forces in the deceleration zone results in $\alpha_{\mathrm{IIb}} \beta_{3}$ engagement corresponding to localized $\mathrm{Ca}^{2+}$ spikes. $\mathrm{Ca}^{2+}$-dependent signaling causes restructuring of filamentous platelet tethers into bulbous morphology, which ultimately stabilizes discoid platelet aggregates. On the thrombus surface, platelets remain loosely adhere via GPIb $\alpha$ without any activation. On the contrary, platelets consolidate in the stable thrombus core via $\alpha_{\mathrm{II}} \beta_{3}$ interactions following weak activation (117).

Westein et al. further elucidated the process of shear gradient-dependent thrombus formation in atherosclerosis by characterizing the central role of VWF in promoting platelet aggregation post-stenosis in both in vivo stenosis models of damaged murine carotid arteries and in vitro microfluidic perfusion assays emulating arterial flow (120). Shear microgradients or elongational flow unfold VWF at forces two orders of magnitude lower compared to constant shear, enhancing platelet recruitment substantially even at low venous flow rates (82). Adhesion of a few circulating platelets by elongated VWF immobilized at the stenosis apex can create a snowball effect with hyper-aggregation of platelets, leading to full vessel occlusion in minutes. Significantly, at shear stress exceeding 100 dynes $/ \mathrm{cm}^{2}$, wherein VWF takes charge of platelet recruitment, aspirin, the gold standard of antiplatelet therapy, is not able to inhibit platelet aggregation, as shown in multiple studies (124-126). Selective COX-2 inhibition even enhanced platelet aggregation under elevated arterial shear stress by reducing the basal production of prostacyclin (prostaglandin $\mathrm{I} 2 ; \mathrm{PGI}_{2}$ ), a potent inhibitor of platelet aggregation especially at high shear stress $(127,128)$.

Overall, it is clear that the shear environment at sites of thrombus formation has a profound effect on various aspects of platelet behavior. In particular, high shear forces induced by the architecture of large thrombi create a feed-forward mechanism that can precipitate occlusive thrombus formation. As such, a better understanding of the shear-dependent aspects of thrombus 


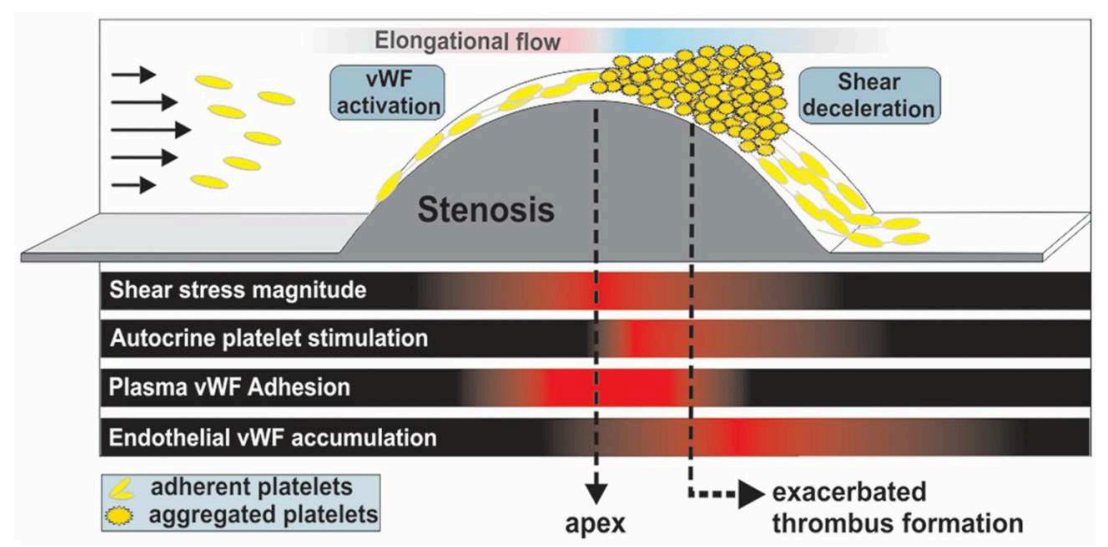

FIGURE 4 | Thrombus formation and propagation is aggravated post-stenosis (simulating atherosclerotic-like geometries) in a WWF-dependent fashion due to shear deceleration, autocrine platelet stimulation and elevated WWF deposition at the stenosis outlet. Adapted with permission from Westein et al. (120).

formation will aid in the design and development of future anti-thrombotic therapies.

\section{THERAPEUTICS TARGETING SHEAR-DEPENDENT THROMBUS FORMATION}

As discussed in the previous sections, shear-dependent VWF unfolding is crucial for initial platelet adhesion, followed by their aggregation and potential formation of a pathological thrombus. Failure of current antithrombotics to effectively prevent pathological thrombosis without bleeding side-effects has been a major obstacle in combating cardiovascular diseases.

Therefore, targeting pathological shear rates that are uniquely present at sites of thrombus development using "smart" therapeutics can be highly effective in preventing total vessel occlusion, significantly improving the efficacy and safety profile of anti-thrombotic therapy.

Two approaches of preventing occlusive thrombi by exploiting pathological shear conditions are discussed hereafter. One approach would be to inhibit shear-driven interaction of the VWF A1 domain and GPIb $\alpha$. The second approach involves shear-sensitive vehicles that specifically target occlusive thrombi due to the abnormally-high shear rates surrounding this environment.

\section{Therapeutics Targeting Shear-Driven VWF A1-GPIb $\alpha$ Interaction}

Considering the diverse pathophysiological impact of the VWFGPIb $\alpha$ interaction, this ligand-receptor pair has been an attractive target in the evolutionary field of antithrombotic therapy. Undeniably, VWF's foremost interaction with the circulating platelet is shear-mediated; therefore, blocking this interaction at pathological shear rates is anticipated to inhibit hyper-aggregation of platelets in the diseased blood vessel, leaving the healthy vessels unaffected. Assorted agents have been designed and tested to target VWF-GPIb $\alpha$ binding under shear conditions, as depicted in Figure 5. The results from preclinical and clinical studies are outlined in Table $\mathbf{1 .}$

\section{AJvW-2}

AJvW-2 is a murine, monoclonal $\mathrm{IgG}_{1}$ directed against the A1 domain of human VWF. It inhibits botrocetin- $\left(\mathrm{IC}_{50}\right.$ $1.8 \pm 0.3 \mu \mathrm{g} \mathrm{ml}^{-1}$ ), ristocetin- ( $\mathrm{IC}_{50} 0.7 \pm 0.1 \mu \mathrm{g} \mathrm{ml}^{-1}$ ), and high shear stress [10.8 Newton meter $\left.(\mathrm{Nm})^{-2}\right]$-induced aggregation, without affecting low shear stress $\left(1.2 \mathrm{Nm}^{-2}\right)$ induced aggregation of human platelets in vitro. The antibody prevented thrombus formation in vivo in photochemicallyinduced arterial thrombosis in carotid artery of guinea pigs, without prolonging the bleeding time (129). The efficacy of AJvW-2 on shear-specific inhibition of VWF-GPIb $\alpha$ interaction was tested in ACS patients (12 with unstable angina, 20 with acute myocardial infarction) with enhanced Shear-Induced Platelet Aggregation (SIPA). Using cone and plate viscometer, SIPA was measured for the patients' blood and the antibody was found to inhibit at $10 \mu \mathrm{g} \mathrm{ml}^{-1}$ high SIPA, without affecting aggregation at low shear stress (130). AJvW-2's prevention of thrombus generation and platelet adhesion within the carotid artery was also observed in guinea pigs, following a balloon catheter injury. Platelet aggregation was significantly inhibited for 2 days and neointima formation was circumvented 14 days following injury (131). The shear-specific blockade of VWF-GPIb $\alpha$ interaction by this monoclonal antibody provided it with an advantage of lower bleeding risk over GPIIb/IIIa antagonists.

\section{AJW200}

AJW200 is the humanized form of the anti-VWF monoclonal antibody, AJvW-2 (above), synthesized to overcome the immunogenicity and rapid clearance of AJvW-2 in humans. In vitro studies using cone and plate viscometer showed the selective suppression of thrombin generation, adhesion and aggregation of human platelets under high shear conditions, but not under low shear conditions. Moreover, the pharmacokinetic (PK) and pharmacodynamic (PD) profiles of AJW200 were investigated ex vivo in cynomolgus monkeys after intravenous 


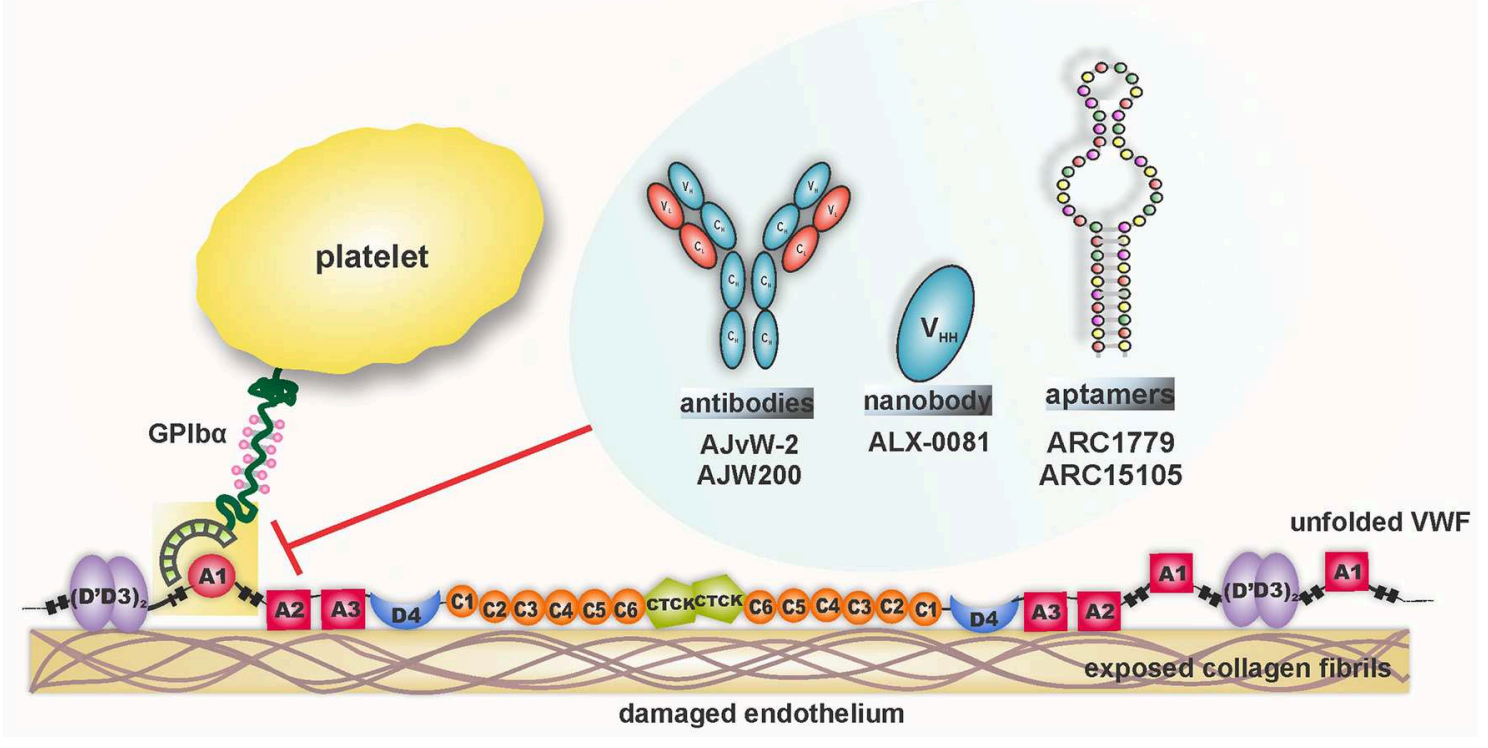

FIGURE 5 | Therapeutics targeting and inhibition of shear-driven WWF A1-GPIb interaction.

administration. Dose-dependent inhibition of ristocetin-induced platelet aggregation was observed without extensively prolonged bleeding times as compared to abciximab (132). In the Folt's model of coronary arterial thrombosis in beagle dogs, significant inhibition of botrocetin-induced platelet aggregation and cyclic flow reductions were observed, but with marked bleeding time prolongation (133). Clinically, dose-dependent inhibition of platelet ristocetin cofactor (RiCof) activity was observed after AJW200 infusion along with an increased Platelet Function Assay (PFA)-100 closure time, with skin bleeding time augmentation (134). While the initial results with AJW200 seemed encouraging, data from the latter has not been published and no further clinical investigations with AJW200 have been reported.

\section{ARC1779}

ARC1779 is a synthetically manufactured aptamer (a short, single-stranded oligonucleotides) against the A1 domain of VWF, that strongly binds with its target ( $\sim 2 \mathrm{nM}$ dissociation constant) to prevent VWF-mediated platelet aggregation.

ARC1779 inhibited botrocetin-induced ( $\left.\mathrm{IC}_{90} \sim 300 \mathrm{nM}\right)$ and high shear-induced ( $\mathrm{IC}_{95} \sim 400 \mathrm{nM}$ ) aggregation of human platelets in vitro. In a study using electrically-induced arterial thrombosis in cynomolgus monkeys, ARC1779 inhibited occlusive thrombus formation with mild bleeding time extension (135). Overall, ARC1779 exhibited comparable antithrombotic efficacy as abciximab with lesser bleeding time prolongations. In a prospective, partial cross-over phase I/II clinical trial, safety and efficacy of ARC1779 were investigated in patients with congenital TTP (137). The results suggested that ARC1779 dosedependently inhibited VWF-triggered platelet plug formation and stabilized the platelet count in TTP patients during infusion, with no associated bleeding events. However, the subcutaneous delivery of the aptamer yielded plasma concentrations that were insufficient to correct all the clinical or laboratory features of TTP (137). Later, a randomized, double-blind, placebo-controlled clinical study was performed in 36 patients undergoing carotid endarterectomy (CEA) to evaluate the immediate effect of ARC1779 on cerebral emboli post CEA (138). Embolic signals (ES), detected by transcranial Doppler ultrasound (TCD), were used to determine the effect of the drug. Rapid reduction of ES signals in terms of mean signal and frequency was seen by ARC1779. However, bleeding and anemic episodes were also reported in this study (138).

\section{ARC15105}

ARC15015 is the second generation, chemically modified, antiVWF aptamer that was designed to target shear-dependent platelet aggregation in the clinical setting of myocardial infarction. Pegylated ARC15015 was developed to substantially enhance the suppression capacity of VWF activity, with increased bioavailability and half-life. ARC15105 completely inhibited ristocetin-induced platelet aggregation in whole blood and caused over $90 \%$ inhibition of platelet adhesion in denuded porcine aortic segments under high shear conditions. In PK and $\mathrm{PD}$ analysis in cynomolgus monkeys, the aptamer inhibited more than $90 \%$ of VWF activity without any spontaneous bleeds throughout the study (139).

\section{ALX-0081/0681}

ALX-0081 or Caplacizumab (INN) is the only drug candidate targeting the VWF A1 domain that has been approved by the FDA to treat adult aTTP patients (136). ALX-0081 is the first in class, humanized, bivalent nanobody that specifically binds to the GPIb $\alpha$ binding site on VWF. Nanobodies are derived from the heavy-chain variable domains $(\mathrm{VHH})$ of naturally occurring 
TABLE 1 | Outline of approaches that inhibit VWF-GPIba interaction specifically under high shear rates.

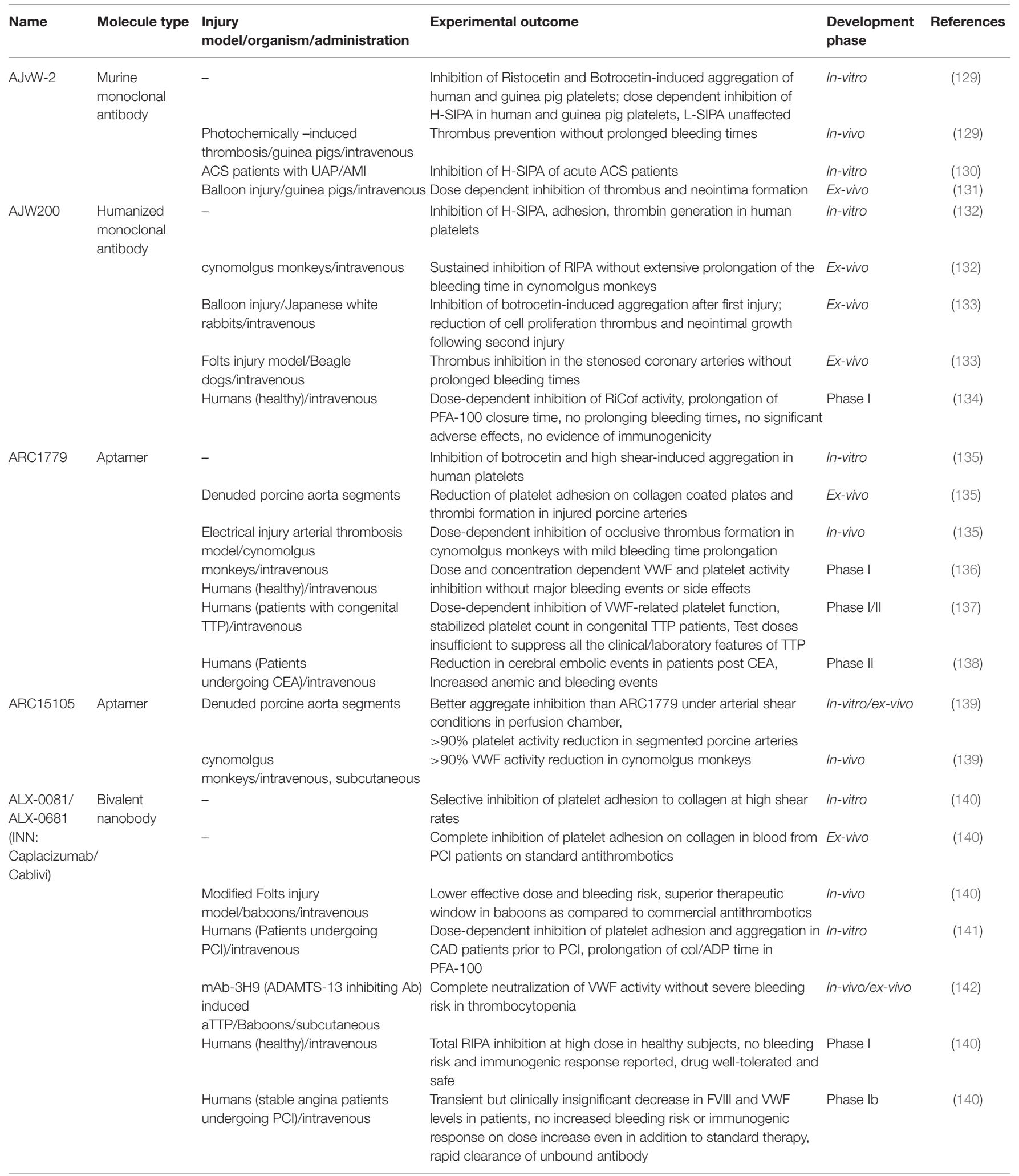


TABLE 1 | Continued

\begin{tabular}{|c|c|c|c|c|c|}
\hline Name & Molecule type & $\begin{array}{l}\text { Injury } \\
\text { model/organism/administration }\end{array}$ & Experimental outcome & $\begin{array}{l}\text { Development } \\
\text { phase }\end{array}$ & References \\
\hline & & $\begin{array}{l}\text { Humans (aTTP patients)/intravenous, } \\
\text { subcutaneous }\end{array}$ & $\begin{array}{l}\text { More rapid resolution of TTP episodes, faster platelet-count } \\
\text { normalization, higher frequency of complete remission and } \\
\text { increased bleeding tendency as compared to placebo }\end{array}$ & $\begin{array}{l}\text { Phase II } \\
\text { (TITAN, } \\
\text { NCT01151423) }\end{array}$ & (143) \\
\hline & & \multirow[t]{2}{*}{$\begin{array}{l}\text { Humans (aTTP } \\
\text { patients)/intravenous, subcutaneous }\end{array}$} & \multirow{2}{*}{$\begin{array}{l}\text { Faster resolution of TTP episode with shorter time to platelet count } \\
\text { response, clinically significant reduction in aTTP recurrence, aTTP } \\
\text { related deaths and major thromboembolic events as compared to } \\
\text { placebo; higher bleeding-related TEAEs than placebo } \\
\text { (Ongoing study) }\end{array}$} & $\begin{array}{l}\text { Phase III } \\
\text { (HERCULES, } \\
\text { NCT02553317) }\end{array}$ & $(144)$ \\
\hline & & & & $\begin{array}{l}\text { Phase Illb } \\
\text { (Post-Hercules, } \\
\text { NCT02878603) }\end{array}$ & - \\
\hline
\end{tabular}

CEA, carotid endarterectomy; PCI, Percutaneous Coronary Intervention; TTP, Thrombotic thrombocytopenic purpura; aTTP, Acquired Thrombotic thrombocytopenic purpura; H-SIPA, High shear-induced platelet aggregation; L-SIPA, Low shear-induced platelet aggregation; Ab, antibody; CAD, Coronary artery disease; RIPA, Ristocetin-induced platelet aggregation; RiCof, Ristocetin cofactor; ACS, Acute coronary syndrome; TEAEs, Treatment-emergent adverse events; UAP, Unstable angina; AMI, Acute myocardial infarction.

camelid heavy chain antibodies. The bi-valency of ALX-0081 equips the nanobody with greater avidity to VWF. In vitro perfusion chamber studies, using blood from healthy individuals and PCI patients receiving standard-of-care treatment (aspirin, clopidogrel, and unfractionated heparin), showed the selective inhibition of platelet adhesion on collagen type III by the nanobody under high, arterial shear conditions (shear rates $>$ $1,500 \mathrm{~s}^{-1}$ ), without any effect under low shear conditions. Plasma levels of 0.3 to $0.5 \mu \mathrm{g} / \mathrm{ml}$ were required for total inhibition of cyclic flow reductions (CFRs) by ALX-0081, corresponding to an effective concentration of $0.8 \mu \mathrm{g} / \mathrm{ml}$ in ACS patients and $0.4 \mu \mathrm{g} / \mathrm{ml}$ in healthy individuals in ex vivo experiments (145). The therapeutic window (the difference between the dose required for CFR and the dose resulting in enhanced bleeding rates) of ALX0081 was found to be superior over abciximab and clopidogrel in baboons. Ristocetin-induced aggregation was inhibited by ALX0081 in healthy individuals (at $0.4 \mu \mathrm{g} / \mathrm{ml}$ ) and in Coronary Artery Disease (CAD) patients (at $0.8 \mu \mathrm{g} / \mathrm{ml}$ ) with higher plasma VWF antigen levels. The nanobody also suppressed platelet adhesion to collagen $(\mathrm{Col})$ under high shear rates and prolonged Col/ADP closure time in PFA-100, both in a dose-dependent fashion (141).

In the setting of TTP, the anti-VWF nanobody rapidly reversed the marked decline in platelet count, along with normalization of lactate dehydrogenase (LDH) levels (which correlates with VWF activity). Most importantly, no drug-related excessive bleeding risks were observed, regardless of reduced VWF activity and platelet count (142). In an open-label extension study, comprising stage $\mathrm{C}$ heart failure patients, an i.v. bolus injection of the drug at $6 \mathrm{mg}$ was administered in 22 Stable Angina (SA) patients. Similar bleeding episodes were observed in the drug-treated and placebo-treated groups, thus proving that ALX-0081 did not result in a greater bleeding risk in these subjects, even in combination with standard antithrombotic therapy. Stable inhibition of VWF-mediated platelet aggregation was found in patients until $30 \mathrm{~h}$ post-multiple administration. Nineteen patients exhibited normal VWF-dependent aggregation of platelets within $48-168 \mathrm{~h}$ post first bolus injection (140). Later, in a Phase II trial (TITAN), 75 acquired TTP patients received caplacizumab (10 mg) and 39 received placebo intravenously, from $6 \mathrm{~h}$ to $15 \mathrm{~min}$ before initiation of plasma exchange. Thereafter, caplacizumab was administered subcutaneously in $10 \mathrm{mg}$ doses daily within half an hour of the exchange. While the time of response (confirmed normalization of platelet count) was the primary end-point of the study, exacerbations and relapses formed major secondary end-points. The daily administration of the drug continued for 30 days following plasma exchange, reaching the maximum duration of 90 days. Impressively, the median response time with the drug decreased by $39 \%$ compared to placebo (median days 2.97 for caplacizumab vs. 4.79 for placebo, $p=0.005$ ), along with an event rate ratio of 2.2 (95\% CI 1.28-3.78, $p-0.005$ ) as compared to the placebo. While 11 patients in the placebo group had exacerbation, only three of the caplacizumab-treated patients showed the same. Within a month of cessation of the study drug, 8 patients had a relapse with baseline ADAMTS13 activity persistently below $10 \%$ in seven of them. This could mean that the underlying autoimmune disorder was not resolved completely (146). Mild to moderate, bleeding-related adverse events were reported at a higher frequency for the caplacizumab-treated group (54\% cases) as compared to the placebo group (38\% cases). However, the bleeding risk was not clinically-significant and the events did not require medical attention.

The results from this trial proved significant in building the case for caplacizumab in fast and sustained resolution of aTTP and paved the way for a phase III clinical trial.

This phase III study-the HERCULES trial-was performed on 145 patients ( 73 receiving placebo, 72 receiving caplacizumab) already receiving daily plasma exchange and corticosteroids. Duration to platelet count response formed the primary endpoint. Seventy-four percentage reduction $(p<0.00001)$ in the occurrence of composite primary endpoints was observed for patients on caplacizumab, with the incidence rate reducing to 12.7 vs. $49.3 \%$ for placebo-treated patients. Bleeding-related Treatment Emergent Adverse Events (TEAE) were 45.6\% ( $n=$ 33) for caplacizumab in comparison to $23.3 \%(n=17)$ for the placebo group. Following these remarkable results from the HERCULES trial, caplacizumab received its first global approval last year (2018) in the European Union for the treatment of adult 
aTTP patients, followed by approval from the US Food and Drug Administration (FDA) $(136,144)$.

In summary, VWF A1-GPIb $\alpha$ binding remains pre-eminent in targeting coronary heart diseases, owing to the elevated levels of VWF specifically in these conditions. Hence, impeding the capacity of VWF to recruit platelets at the injured arterial wall is a crucial factor in designing new anti-platelet regimens. Despite the substantial efforts to specifically target the VWF-GPIb $\alpha$ axis as described above, and notwithstanding the promising, preliminary preclinical and clinical results, no other inhibitors except ALX-0081 have received clinical approval so far.

Local shear-gradients have recently been recognized as the critical driving force behind pathological platelet aggregation, ultimately resulting in insidious thrombus formation. However, their paramount significance in thrombosis has been underplayed from the perspective of their exploitation for novel anti-thrombotic drug designs. Targeting the thrombosisspecific shear microgradients may prove to be the cornerstone in the field of antithrombotic therapeutics. While various direct anti-VWF agents are being developed (above), another approach is utilizing "smart" shear-responsive vehicles to locally deliver current anti-platelet drugs to sites of pathological thrombus formation, as we specify next.

\section{Shear-Sensitive Drug Delivery Platforms Targeting Occlusive Thrombi}

Cardiovascular manifestations resulting from exacerbated thrombus formation are fundamentally distinct from physiological thrombus formation because of the abnormally high and complex blood shear forces associated with the latter. Exploitation of this spatially confined high shear environment could be achieved by delivering anti-thrombotic drugs using "smart," shear-sensitive vehicles. Targeted delivery of current drugs, leveraging these unique shear forces, could improve the therapeutic out-turn of traditional anti-thrombotic drugs by resolving their associated bleeding limitations. Different shear-sensitive platforms have been outlined in Table 2 and are depicted in Figure 6. Those therapeutics, which have been reviewed elsewhere $(147,152-154)$, will be discussed briefly in this section.

\section{Shear-Activated Nanoparticle Aggregates}

Korin and colleagues engineered micron-sized ( $1-5 \mu \mathrm{m})$, shearactivated nanotherapeutics (SA-NTs) or microscale aggregates from poly(lactic-co-glycolic acid), composed of smaller shearactivated nanoparticles (SA-NPs, $\sim 200 \mathrm{~nm}$ ) to target constricted, diseased blood vessels. The SA-NTs maintain a size similar to platelets, to circulate peripherally along the vessel wall, encountering minimal flow velocity and maximal shear rate (49).

The micro-sized aggregates are unique in their ability to breakdown only under pathologically-high shear rates, remaining intact under physiological shear. Consolidated via weak Van der Waals interactions among the constitutive nanoparticles, the aggregates disintegrate in the presence of overpowering shear forces at the pathological thrombus site. Following shear-triggered disintegration of the aggregates, disseminated nanoparticles (facing much lower hydrodynamic drag than the larger microaggregates) accumulate downstream of the stenosis, thereby releasing the cargo.

In the mesenteric ferric chloride-induced injury model, the intravenous administration of tissue-type plasminogen activator (t-PA)-coated SA-NPs resulted in rapid clot dissolution (within $5 \mathrm{~min}$ ). Bolus injection of SA-NTs coated with $50 \mathrm{ng}$ t-PA almost doubled the time to vessel occlusion vs. free, soluble tPA at the same concentration. In a typically-fatal pulmonary embolism model in the mouse, almost $86 \%$ survival rate was observed in mice injected with t-PA-coated SA-NPs. Significantly reduced effective concentration of t-PA was indicated by the SA-NTs, that normalized pulmonary arterial pressure at a 100times lower drug concentration than the control conditions (free drug). Targeted delivery of t-PA via SA-NPs, specifically to stenotic sites, can result in higher localized drug concentrations at stenotic sites without increased systemic concentrations of free drug, leading to lower hemorrhagic complications. So far, favorable results obtained from various in vitro, ex vivo, and in vivo models have illustrated the pre-clinical advantages of employing these engineered SA-NPs in achieving targeted delivery of the thrombolytic drug in a safe and effective manner. However, further investigations are essential to determine whether this targeting approach could be translated to the clinical setting. Furthermore, other clinically-approved antiplatelet and antithrombotic agents could also be loaded onto SA-NTs to prevent thrombosis.

\section{Shear-Sensitive Liposomes or Vesicles}

Liposomes are spherical vesicles $(100-250 \mathrm{~nm}$ in diameter), consisting of an aqueous core surrounded by a phospholipid bilayer. Over the years, liposomal nanocapsules (NCs) have provided enormous opportunities in targeted drug delivery by their unique ability to load and stabilize a plethora of hydrophilic and hydrophobic drugs (155-158). In general, liposomes possess spherical morphology due to its minimum energy and maximum stability (159). This morphology imparts robustness to the vesicles against mechanical disruption. Bernard et al. demonstrated shear-induced membrane permeability in unilamellar, egg phosphatidyl choline (EPC) vesicles (50$400 \mathrm{~nm}$ ) using a non-ionic surfactant, Brij 76 . The study provided an experimental proof that on addition of detergents, membrane leakage can be induced by shear. Greater shear-driven membrane leakage was observed for large, unilamellar vesicles (LUVs) as compared to the smaller ones, in the presence of Brij 76 (160). Holme et al. fabricated non-spherical, lenticular vesicles (Pad-PC-Pad) exhibiting a relatively larger bending moduli and curvature around the equator, that could lead to transient pore formation under elevated shear stress. The lenticular morphology of these liposomes could increase their sensitivity toward higher shear levels. The liposomes were able to release the loaded fluorescent dye, carboxyfluorescein, under mechanical shaking even without the surfactant. However, no leakage of the liposomes was observed in the absence of mechanically disruptive forces. An extracorporeal circulation model was designed to mimic physiological and pathological (75\% lumen restriction) arterial flow conditions with the shear stresses of $2 \mathrm{~Pa}$ and about $40 \mathrm{~Pa}$, respectively. A clear, shear-specific fluorescent dye release 
TABLE 2 | Outline of shear-sensitive drug delivery platforms targeting occluded blood vessels.

\begin{tabular}{|c|c|c|c|c|c|c|c|c|}
\hline $\begin{array}{l}\text { Delivery } \\
\text { platform }\end{array}$ & $\begin{array}{l}\text { Carrier } \\
\text { composition }\end{array}$ & $\begin{array}{l}\text { Carrier } \\
\text { morphology }\end{array}$ & $\begin{array}{l}\text { Biologically active } \\
\text { agent/loading } \\
\text { method }\end{array}$ & Targeted site & $\begin{array}{l}\text { Experimental } \\
\text { setup }\end{array}$ & $\begin{array}{l}\text { Experimental } \\
\text { model }\end{array}$ & Experimental outcome & References \\
\hline \multicolumn{9}{|c|}{ Nanoparticle aggregates } \\
\hline \multirow[t]{2}{*}{ SA-NTS } & PLGA & $\begin{array}{l}3.8 \pm 1.6 \mu \mathrm{m} \\
\text { aggregates } \\
\text { composed of } \\
180 \pm 70 \mathrm{~nm} \\
\mathrm{NPs}\end{array}$ & $\begin{array}{l}\text { tPA/coating } \\
\text { r-tPA }\end{array}$ & $\begin{array}{l}\text { Occluded } \\
\text { mesentery artery }\end{array}$ & In vivo & $\begin{array}{l}\text { Mouse arterial } \\
\text { thrombus } \\
\text { model }\end{array}$ & $\begin{array}{l}\text { Total dissolution of } \\
\text { thrombus within } 5 \text { min of } \\
\text { local administration }\end{array}$ & $(147)$ \\
\hline & & $\begin{array}{l}4 \mu \mathrm{m} \text { aggregates } \\
\text { composed of } \\
\sim 200 \mathrm{~nm} \text { NPs }\end{array}$ & & $\begin{array}{l}\text { Occluded } \\
\text { pulmonary artery }\end{array}$ & In vivo & $\begin{array}{l}\text { Mouse PE } \\
\text { model }\end{array}$ & $\begin{array}{l}\text { Reinstatement of arterial } \\
\text { flow with } \sim 86 \% \text { survival } \\
\text { rate in mice post } \\
\text { administration }\end{array}$ & $(147)$ \\
\hline $\begin{array}{l}\text { SA-NTs } \\
\text { (combined } \\
\text { with TEB) }\end{array}$ & PLGA & & & $\begin{array}{l}\text { Occluded } \\
\text { carotid artery }\end{array}$ & In vivo & $\begin{array}{l}\text { Rabbit carotid } \\
\text { vessel } \\
\text { occlusion model }\end{array}$ & $\begin{array}{l}\text { Higher rate of complete } \\
\text { recanalization of ELVO } \\
\text { with r-tPA coated SA-NTs } \\
\text { with TEB, significantly less } \\
\text { vascular trauma than } \\
\text { stent-retriever TM }\end{array}$ & $(148)$ \\
\hline \multicolumn{9}{|l|}{ Liposomes } \\
\hline $\begin{array}{l}\text { Lenticular } \\
\text { vesicles }\end{array}$ & Pad-PC-Pad & $\begin{array}{l}\text { Lenticular, } \\
100 \mathrm{~nm}\end{array}$ & [5(6)-FAM] & - & $\begin{array}{l}\text { In-vitro } \\
\text { (extracorporeal } \\
\text { pump flow } \\
\text { setup) }\end{array}$ & - & $\begin{array}{l}\text { Selective payload (dye) } \\
\text { release in stenosed arterial } \\
\text { model at high shear }\end{array}$ & $(149)$ \\
\hline Nanocapsules & Egg-PC & $\sim 200 \mathrm{~nm}$ & $\begin{array}{l}\text { Eptifibatide/ } \\
\text { encapsulation }\end{array}$ & $\begin{array}{l}\text { Occluded } \\
\text { carotid artery }\end{array}$ & In-vivo & $\begin{array}{l}\text { Mouse carotid } \\
\text { vessel } \\
\text { occlusion model }\end{array}$ & $\begin{array}{l}\text { Reduction of pulmonary } \\
\text { thrombus load without } \\
\text { prolonged bleeding times } \\
\text { in mice }\end{array}$ & $(150)$ \\
\hline
\end{tabular}

SA-NTS, shear-activated nanotherapeutics; SA-NPS, shear-activated nanoparticles; NPS, nanoparticles; PLGA, poly(lactic-co-glycolic acid); tPA, tissue plasminogen activator; PE, pulmonary embolism; TEB, temporary endovascular bypass; $r$-tPA, recombinant tissue plasminogen activator; ELVO, emergent large vessel occlusion; TM, thromboectomy; FAM, carboxyfluorescein (model-dye); Pad-PC-Pad, 1,3-dipalmitamidopropan-2-yl 2-(trimethylammonio)ethyl phosphate; PC, phosphatidylcholine.

was observed for the Pad-PC-Pad liposomes, with $45.5 \pm 11 \%$ payload release in the healthy arteries and $70 \pm 2.3 \%$ release in the constricted arteries after one passage only. In comparison, the fluorophore release by the egg PC liposomal formulations was below $10 \%$ after one passage. These promising in vitro results for the Pad-PC-Pad liposomes highlight their potential in the area of targeted, shear-specific delivery to the occluded vessels in MI patients (149).

Recently, Molloy et al. (150) formulated shear-sensitive egg phosphatidylcholine (PC) liposomes that targeted the clinical antiplatelet drug, eptifibatide, to the local thrombus site. In vitro blood perfusion assays were done in stenotic microchannels emulating stenotic shear conditions. The liposomes released eptifibatide at stenotic sites with governing shear rates of $\sim 8,000 \mathrm{~s}^{-1}$, inhibiting platelet aggregation specifically in the narrowed region without effects on thrombus volume in regions of lower shear $\left(\sim 1,000 \mathrm{~s}^{-1}\right)$. Modulation of the shear-sensitive drug release properties of the nanocapsules was demonstrated by incorporating Brij 76 in the formulations, reducing the liposomal shear-threshold from over $1,500 \mathrm{~s}^{-1}$ to between 500 and $1,000 \mathrm{~s}^{-1}$. When applied in vivo in a carotid artery occlusion mouse model, the shear-sensitive, eptifibatide-loaded liposomes significantly reduced thrombus load as compared with free eptifibatide, without any prolongation of bleeding times. This safety profile has most likely been achieved by the marked reduction in systemic eptifibatide concentrations, enabled by the targeted drug-release approach.
Surface functionalization of shear-sensitive liposomes with targeting moieties could actively direct the liposomes toward thrombi in vivo, further lowering the required dosage. Sitespecific delivery of anti-platelet drugs could increase the local drug concentration at the stenosed vessel region without posing major bleeding risks.

In summary, liposomes can serve as an ideal carrier of an unprecedented range of antithrombotic agents, given the versatility of their physical and chemical structures and tunable functionality of the lipid surfaces to achieve desired physiological stimuli responsiveness. Tailoring their mechanical properties to induce sensitivity to pathological shear forces may result in efficacious, targeted drug delivery platform. Proof-of-concept studies have already shown promising results of liposomal drug delivery to constricted vessels with an increased local drug concentration. Drug dosage can be further reduced by chemical or biological modifications of liposomes via targeting moieties that direct the payload to the stenotic site, thereby attenuating thrombus progression (161-163).

\section{CONCLUSION AND CURRENT CLINICAL CHALLENGES}

VWF is an attractive, shear-sensitive target for drug delivery due to its altered biophysical properties under the pathological 


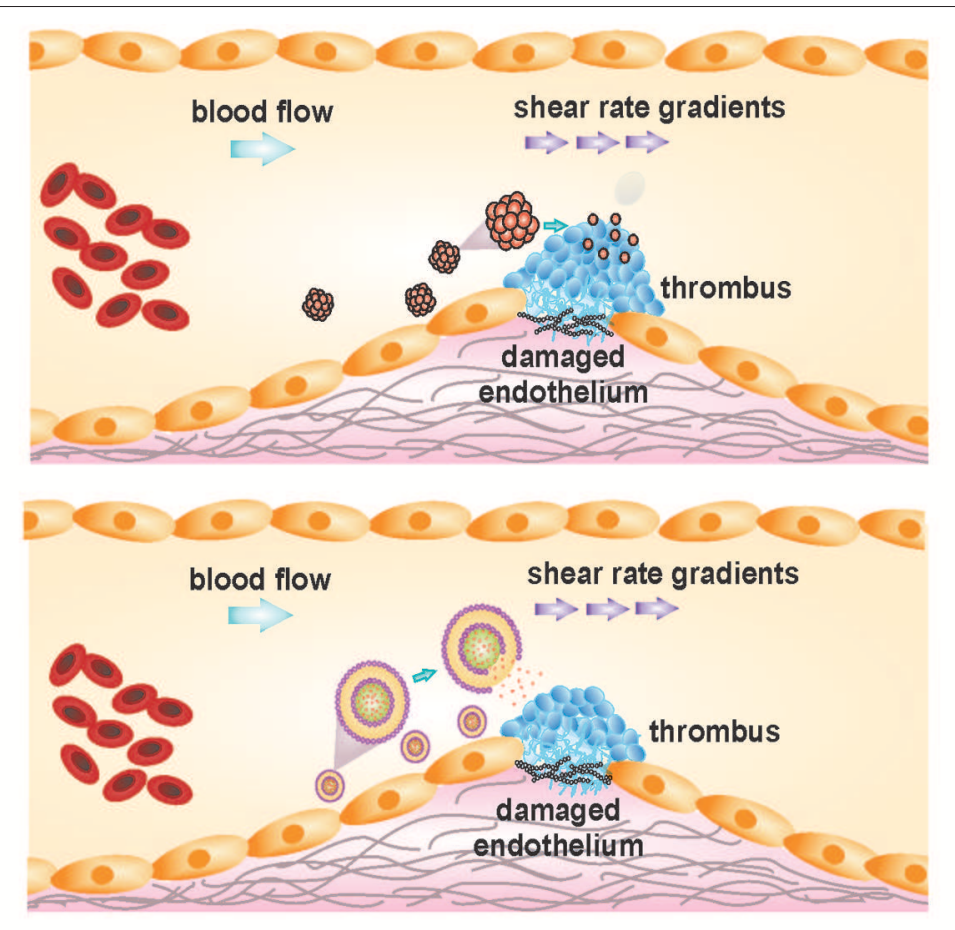

endothelial cell sub-endothelial collagen won Willebrand factor discoid platelet $\&$ activated platelet shear-sensitive liposomes

FIGURE 6 | Shear-sensitive drug delivery platforms targeting occlusive thrombus formation. Adapted and modified from Westein et al. (151) with permission from the publisher.

hemodynamic microenvironment, leading to hyper-aggregation of platelets in thrombotic events. Selective targeting of the VWF binding sites with platelet receptors could prove safer and more effective than systemic inhibition of platelet function via current antiplatelet drugs. Several agents targeting VWF under high shear conditions have been developed, yet despite initial success in some reports many challenges still require resolution for future clinical use. For example, in vitro assays and in vivo models emulating shear microenvironments in blood vessels adopt an over-simplified approach, while the physiological blood rheology and microvasculature vastly differ within and among organisms. This may account for the all too often failure to reproduce encouraging preclinical findings in clinical trials, seen with a number of compounds to-date.

Current blood coagulation tools, including tail bleeding time, skin puncture test, activated partial thromboplastin time (APTT), prothrombin time (PT) or platelet aggregometry do not incorporate biomechanical aspects of thrombosis, i.e., shear stress (164-166). The inability of the standard testing tools to embed the effects of local shear rates and shear rate gradients limits their assessment accuracy in the clinical settings. Rheological devices, such as parallel plate flow chambers and microfluidic blood perfusion channels coated with extracellular matrix proteins, can effectively emulate the pathological shear conditions in stenotic vessels. These devices provide versatile platforms with customizable flow and coating conditions, using minuscule blood volumes, to optimally indicate the net coagulative state of a given sample when all major pathways are in place $(117,120,167,168)$.

Several considerations should be taken in account when designing a novel shear-sensitive therapy, including the choice of a suitable, biologically-active compound(s), the need to tailor the shear sensitivity of a given template for maximum drug release without amplifying any negative effects, and the requirement to tune the circulation times ("half-life") according to the drug's therapeutic window. This can be a challenging task, as most nanoparticles are immediately uptaken and rapidly cleared by the reticuloendothelial system (RES). Opsonization and immunogenicity can be other obstacles for in vivo utilization of these nano-agents (169). Therefore, optimization of particle hydrodynamic diameter, surface morphology and functionality can prolong their circulation times in blood to attain the desired therapeutic effect. PEGylation can also result in stealth nanoparticles with longer half-lives (169). Toxicity is yet another problem associated with nanoparticles, that can be significantly reduced or completely avoided by opting for natural compounds instead of synthetic ones (170). Storage stability as well as scale-up feasibility of nanoparticles can pose additional challenges in their production. Selecting a simple, cost-effective and easily reproducible production 
strategy can offer some remedy for these issues (171). Despite these challenges, nanoparticles are increasingly used in clinical applications (172).

\section{FUTURE PERSPECTIVES}

For decades, the focus of anti-platelet drug development has been on platelet activation pathways induced by soluble agonists and ligand binding $(173,174)$. In recent years, the concept of complex shear forces, which contribute to pathological thrombus formation, has gained traction in multiple studies using sophisticated mouse models $(175,176)$ as well as in vitro blood perfusion flow assays $(4,117,120)$ and novel singlemolecule techniques $(7,108,177,178)$. Nevertheless, so far these studies have not resulted in any translation into shear selective therapies.

The role of shear, and in particular gradients of shear, in driving VWF-GPIb $\alpha$-dependent thrombus formation in cardiovascular diseases has become apparent. The difference in propensity of VWF-GPIb $\alpha$ interaction under constant, physiological shear rates and pathological shear gradients can be crucial in distinguishing between the life-saving process of hemostasis and the life-threatening process of thrombosis. Selective interference with the VWF-GPIb $\alpha$ axis under shear gradients may not only increase the efficacy of future anti-thrombotic agent, but potentially resolve the most dangerous limitation of current therapeutics, being bleeding complications.

Several strategies that selectively target VWF A1-GPIb $\alpha$ binding under high shear rates have been developed, including antibodies (AJvW-2, AJW200), aptamers (ARC1779,

\section{REFERENCES}

1. Bizzozero G. Su di un nuovo elemento morfologico del sangue dei mammiferi e della sua importanza nella trombosi e nella coagulazione. L'Osservatore. (1881) 17:785-7.

2. Paulus JM. Platelet size in man. Blood. (1975) 46:321-36.

3. Quach ME, Chen W, Li R. Mechanisms of platelet clearance and translation to improve platelet storage. Blood. (2018) 131:1512-21. doi: 10.1182/blood-2017-08-743229

4. Maxwell MJ, Westein E, Nesbitt WS, Giuliano S, Dopheide SM, Jackson SP. Identification of a 2-stage platelet aggregation process mediating shear-dependent thrombus formation. Blood. (2007) 109:566-76. doi: 10.1182/blood-2006-07-028282

5. Jackson SP, Nesbitt WS, Westein E. Dynamics of platelet thrombus formation. J Thromb Haemost. (2009) 7(Suppl. 1):17-20. doi: 10.1111/j.1538-7836.2009.03401.x

6. Kang I, Raghavachari M, Hofmann CM, Marchant RE. Surfacedependent expression in the platelet GPIb binding domain within human von Willebrand factor studied by atomic force microscopy. Thromb Res. (2009) 119:731-40. doi: 10.1016/j.thromres.2006. 06.010

7. Ju L, Chen Y, Zhou F, Lu H, Cruz MA, Zhu C. Von Willebrand factor-A1 domain binds platelet glycoprotein Ib $\alpha$ in multiple states with distinctive force-dependent dissociation kinetics. Thromb Res. (2015) 136:606-12. doi: 10.1016/j.thromres.2015.06.019

8. Jung SM, Moroi M. Platelet glycoprotein VI. Adv Exp Med Biol. (2008) 640:53-63. doi: 10.1007/978-0-387-09789-3_5
ARC15105), and nanobodies (ALX-0081). In a related strategy, shear-sensitive "smart" nanoparticles have been produced to target vessel occlusions, including nanoparticle aggregates and liposomes. Although further studies are required to validate the efficacy and safety of these therapeutic nanotechnologies, preliminary results have been highly promising.

Taken together, nanoparticles exhibit unique physical, chemical, structural, and biological properties, which can be harnessed to revolutionize the field of thrombosis. Nanoparticles versatility truly offers immense possibilities for surface modification and functionalization to suit the desired application. Nano formulations indeed provide great opportunities for targeted drug delivery due to their high drug payload capacity, reduced antigenicity and prolonged plasma half-life (179-182). Lower effective dosage and higher localization of the drug at the affected sites may prove critical in addressing the age-old bleeding issues. Although the full potential of shear-sensitive antithrombotic/antiplatelet therapy is yet to be clinically realized, shear-responsive strategies are destined to transform the future of thrombosis.

\section{AUTHOR CONTRIBUTIONS}

AR has drafted the first version of the paper and all other authors $(\mathrm{CH}, \mathrm{BN}$, and $\mathrm{EW})$ have reviewed and revised the review.

\section{FUNDING}

This work was support by the National Health and Medical Research Council of Australia.

9. Staatz WD, Walsh JJ, Pexton T, Santoro SA. The alpha 2 beta 1 integrin cell surface collagen receptor binds to the alpha 1 (I)-CB3 peptide of collagen. $J$ Biol Chem. (1990) 265:4778-81.

10. Farndale RW, Sixma JJ, Barnes MJ, De Groot PG. The role of collagen in thrombosis and hemostasis. J Thromb Haemost. (2004) 2:561-73. doi: 10.1111/j.1538-7836.2004.00665.x

11. Moskalensky AE, Litvinenko AL. The platelet shape change: biophysical basis and physiological consequences. Platelets. (2019) 30:543-8. doi: 10.1080/09537104.2018.1514109

12. Golebiewska EM, Poole AW. Platelet secretion: from haemostasis to wound healing and beyond. Blood Rev. (2015) 29:153-62. doi: 10.1016/j.blre.2014.10.003

13. Blair P, Flaumenhaft R. Platelet alpha-granules: basic biology and clinical correlates. Blood Rev. (2009) 23:177-89. doi: 10.1016/j.blre.2009.04.001

14. Macfarlane DE, Walsh PN, Mills DC, Holmsen H, Day HJ. The role of thrombin in ADP-induced platelet aggregation and release: a critical evaluation. Br J Haematol. (1975) 30:457-63. doi: 10.1111/j.1365-2141.1975.tb01860.x

15. Harrison P, Martin Cramer E. Platelet $\alpha$-granules. Blood Rev. (1993) 7:52-62. doi: 10.1016/0268-960X(93)90024-X

16. Ma YQ, Qin J, Plow EF. Platelet integrin alpha(IIb)beta(3): activation mechanisms. J Thromb Haemost. (2007) 5:1345-52. doi: 10.1111/j.1538-7836.2007.02537.x

17. Vickers JD. Binding of polymerizing fibrin to integrin alpha IIb beta 3 on chymotrypsin-treated rabbit platelets decreases phosphatidylinositol 4,5-bisphosphate and increases cytoskeletal actin. Platelets. (1999) 10:22837. doi: 10.1080/09537109976077 
18. Gale AJ. Continuing education course \#2: current understanding of hemostasis. Toxicol Pathol. (2011) 39:273-80. doi: $10.1177 / 0192623310389474$

19. Adams HP Jr. Secondary prevention of atherothrombotic events after ischemic stroke. Mayo Clin Proc. (2009) 84:43-51. doi: 10.4065/84.1.43

20. Papp J, Kenyeres P, Toth K. Clinical importance of antiplatelet drugs in cardiovascular diseases. Clin Hemorheol Microcirc. (2013) 53:81-96. doi: 10.3233/CH-2012-1578

21. Angiolillo DJ. Variability in responsiveness to oral antiplatelet therapy. Am J Cardiol. (2009) 103:27a-34a. doi: 10.1016/j.amjcard.2008.11.020

22. Kuliczkowski W, Witkowski A, Polonski L, Watala C, Filipiak K, Budaj $A$, et al. Interindividual variability in the response to oral antiplatelet drugs: a position paper of the Working Group on antiplatelet drugs resistance appointed by the Section of Cardiovascular Interventions of the Polish Cardiac Society, endorsed by the Working Group on Thrombosis of the European Society of Cardiology. Eur Heart J. (2009) 30:426-35. doi: 10.1093/eurheartj/ehn562

23. Sofi F, Marcucci R, Gori AM, Giusti B, Abbate R, Gensini GF. Clopidogrel non-responsiveness and risk of cardiovascular morbidity. An updated metaanalysis. Thromb Haemost. (2010) 103:841-8. doi: 10.1160/TH09-06-0418

24. Di Minno MND, Guida A, Camera M, Colli S, Di Minno G, Tremoli E. Overcoming limitations of current antiplatelet drugs: a concerted effort for more profitable strategies of intervention. Ann Med. (2011) 43:531-44. doi: 10.3109/07853890.2011.582137

25. Verheugt FWA. In search of a better platelet ADP-receptor blocker. Neth Heart J. (2009) 17:188-9. doi: 10.1007/BF03086244

26. Ferro A. Newer antiplatelet agents in acute coronary syndrome. BMJ. (2016) 352:h7025. doi: 10.1136/bmj.h7025

27. Paradiso-Hardy FL, Angelo CM, Lanctôt KL, Cohen EA. Hematologic dyscrasia associated with ticlopidine therapy: evidence for causality. Can Med Assoc J. (2000) 163:1441-8.

28. Eikelboom JW, Hirsh J, Weitz JI, Johnston M, Yi Q, Yusuf S. Aspirinresistant thromboxane biosynthesis and the risk of myocardial infarction, stroke, or cardiovascular death in patients at high risk for cardiovascular events. Circulation. (2002) 105:1650-5. doi: 10.1161/01.CIR.0000013777. 21160.07

29. Pedersen AK, Fitzgerald GA. Dose-related kinetics of aspirin. Presystemic acetylation of platelet cyclooxygenase. N Engl J Med. (1984) 311:1206-11. doi: 10.1056/NEJM198411083111902

30. Kastrati A, Schomig A, Schomig E. Are we making efficient use of clopidogrel? Eur Heart J. (2004) 25:454-6. doi: 10.1016/j.ehj.2004.02.005

31. Husted S. Benefits and risks with antiplatelet therapy: how great a problem is bleeding? Eur Heart J Suppl. (2008) 10:I19-24. doi: 10.1093/eurheartj/sun036

32. Antithrombotic Trialists C, Baigent C, Blackwell L, Collins R, Emberson J, Godwin J, et al. Aspirin in the primary and secondary prevention of vascular disease: collaborative meta-analysis of individual participant data from randomised trials. Lancet. (2009) 373:1849-60. doi: 10.1016/S0140-6736(09)60503-1

33. Farre AJ, Tamargo J, Mateos-Caceres PJ, Azcona L, Macaya C. Old and new molecular mechanisms associated with platelet resistance to antithrombotics. Pharm Res. (2010) 27:2365-73. doi: 10.1007/s11095-010-0209-4

34. Tsai Thomas T, Ho PM, Xu S, Powers JD, Carroll Nikki M, Shetterly Susan $\mathrm{M}$, et al. Increased risk of bleeding in patients on clopidogrel therapy after drug-eluting stents implantation. Circulation. (2010) 3:230-5. doi: 10.1161/CIRCINTERVENTIONS.109.919001

35. Patrono C, Coller B, Fitzgerald GA, Hirsh J, Roth G. Platelet-active drugs: the relationships among dose, effectiveness, and side effects: the seventh ACCP Conference on antithrombotic and thrombolytic therapy. Chest. (2004) 126:234s-64s. doi: 10.1378/chest.126.3_suppl.234S

36. Germing A, Bojara W, Lawo T, Ewers A, Grewe P, Mügge A, et al. Bleeding complications associated with glycoprotein IIb/IIIa inhibitors in patients 80 years of age and older undergoing percutaneous coronary intervention. Exp Clin Cardiol. (2010) 15:e57-60.

37. Nussmeier NA, Whelton AA, Brown MT, Langford RM, Hoeft A, Parlow JL, et al. Complications of the COX-2 inhibitors parecoxib and valdecoxib after cardiac surgery. $N$ Engl J Med. (2005) 352:1081-91. doi: 10.1056/NEJMoa050330
38. Solomon SD, Mcmurray JJV, Pfeffer MA, Wittes J, Fowler R, Finn P, et al. Cardiovascular risk associated with celecoxib in a clinical trial for colorectal adenoma prevention. N Engl J Med. (2005) 352:1071-80. doi: 10.1056/NEJMoa050405

39. Sabatine MS, Cannon CP, Gibson CM, López-Sendón JL, Montalescot G, Theroux P, et al. Addition of clopidogrel to aspirin and fibrinolytic therapy for myocardial infarction with ST-segment elevation. N Engl J Med. (2005) 352:1179-89. doi: 10.1056/NEJMoa050522

40. Yusuf S, Zhao F, Mehta SR, Chrolavicius S, Tognoni G, Fox KK, et al. Effects of clopidogrel in addition to aspirin in patients with acute coronary syndromes without ST-segment elevation. N Engl J Med. (2001) 345:494-502. doi: 10.1056/NEJMoa010746

41. Levine GN, Bates ER, Bittl JA, Brindis RG, Fihn SD, Fleisher LA, et al. 2016 ACC/AHA guideline focused update on duration of dual antiplatelet therapy in patients with coronary artery disease: a report of the American College of Cardiology/American Heart Association Task Force on Clinical Practice Guidelines. J Thorac Cardiovasc Surg. (2016) 152:1243-75. doi: 10.1016/j.jtcvs.2016.07.044

42. Bittl JA, Baber U, Bradley SM, Wijeysundera DN. Duration of dual antiplatelet therapy: a systematic review for the 2016 ACC/AHA guideline focused update on duration of dual antiplatelet therapy in patients with coronary artery disease: a report of the American college of cardiology/American heart association task force on clinical practice Guidelines. J Am Coll Cardiol. (2016) 68:1116-39. doi: 10.1016/j.jacc.2016.03.512

43. Wilson SJ, Newby DE, Dawson D, Irving J, Berry C. Duration of dual antiplatelet therapy in acute coronary syndrome. Heart. (2017) 103:573. doi: 10.1136/heartjnl-2016-309871

44. Hansen ML, Sorensen R, Clausen MT, Fog-Petersen ML, Raunso J, Gadsboll N, et al. Risk of bleeding with single, dual, or triple therapy with warfarin, aspirin, and clopidogrel in patients with atrial fibrillation. Arch Intern Med. (2010) 170:1433-41. doi: 10.1001/archinternmed.20 10.271

45. Dans AL, Connolly SJ, Wallentin L, Yang S, Nakamya J, Brueckmann $\mathrm{M}$, et al. Concomitant use of antiplatelet therapy with dabigatran or warfarin in the Randomized Evaluation of Long-Term Anticoagulation Therapy (RE-LY) trial. Circulation. (2013) 127:634-40. doi: 10.1161/CIRCULATIONAHA.112.115386

46. Strony J, Beaudoin A, Brands D, Adelman B. Analysis of shear stress and hemodynamic factors in a model of coronary artery stenosis and thrombosis. Am J Physiol. (1993) 265:H1787-96. doi: 10.1152/ajpheart.1993.265.5.H1787

47. Sakariassen KS, Orning L, Turitto VT. The impact of blood shear rate on arterial thrombus formation. Future Sci OA. (2015) 1:FSO30. doi: $10.4155 /$ fso. 15.28

48. Kroll MH, Hellums JD, Mcintire LV, Schafer AI, Moake JL. Platelets and shear stress. Blood. (1996) 88:1525-41.

49. Goldsmith HL, Turitto VT. Rheological aspects of thrombosis and haemostasis: basic principles and applications. ICTH-report-subcommittee on rheology of the international committee on thrombosis and haemostasis. Thromb Haemost. (1986) 55:415-35. doi: 10.1055/s-0038-16 61576

50. Livio M, Gotti E, Marchesi D, Mecca G, Remuzzi G, De Gaetano G. Uraemic bleeding: role of anaemia and beneficial effect of red cell transfusions. Lancet. (1982) 2:1013-5. doi: 10.1016/S0140-6736(82)90050-2

51. Lipowsky HH, Kovalcheck S, Zweifach BW. The distribution of blood rheological parameters in the microvasculature of cat mesentery. Circ Res. (1978) 43:738-49. doi: 10.1161/01.RES.43.5.738

52. Goldsmith HL, Cokelet GR, Gaehtgens P. Robin Fahraeus: evolution of his concepts in cardiovascular physiology. Am J Physiol. (1989) 257:H1005-15. doi: 10.1152/ajpheart.1989.257.3.H1005

53. Basmadjian D. The effect of flow and mass transport in thrombogenesis. Ann Biomed Eng. (1990) 18:685-709. doi: 10.1007/BF02368455

54. Gogia S, Neelamegham S. Role of fluid shear stress in regulating VWF structure, function and related blood disorders. Biorheology. (2015) 52:319-35. doi: 10.3233/BIR-15061

55. Sakariassen KS. Thrombus formation on apex of arterial stenoses: the need for a fluid high shear stenosis diagnostic device. Future Cardiol. (2007) 3:193-201. doi: 10.2217/14796678.3.2.193 
56. Dopheide SM, Maxwell MJ, Jackson SP. Shear-dependent tether formation during platelet translocation on von Willebrand factor. Blood. (2002) 99:159. doi: 10.1182/blood.V99.1.159

57. Savage B, Saldivar E, Ruggeri ZM. Initiation of platelet adhesion by arrest onto fibrinogen or translocation on von Willebrand factor. Cell. (1996) 84:289-97. doi: 10.1016/S0092-8674(00)80983-6

58. Ikeda Y, Handa M, Kawano K, Kamata T, Murata M, Araki Y, et al. The role of von Willebrand factor and fibrinogen in platelet aggregation under varying shear stress. J Clin Invest. (1991) 87:1234-40. doi: 10.1172/JCI115124

59. Kulkarni S, Dopheide SM, Yap CL, Ravanat C, Freund M, Mangin P, et al. A revised model of platelet aggregation. J Clin Invest. (2000) 105:783-91. doi: 10.1172/JCI7569

60. Titani K, Kumar S, Takio K, Ericsson LH, Wade RD, Ashida K, et al. Amino acid sequence of human von Willebrand factor. Biochemistry. (1986) 25:3171-84. doi: 10.1021/bi00359a015

61. Ruggeri ZM. Structure of von Willebrand factor and its function in platelet adhesion and thrombus formation. Best Pract Res Clin Haematol. (2001) 14:257-79. doi: 10.1053/beha.2001.0133

62. Shankaran H, Alexandridis P, Neelamegham S. Aspects of hydrodynamic shear regulating shear-induced platelet activation and self-association of von Willebrand factor in suspension. Blood. (2003) 101:2637-45. doi: 10.1182/blood-2002-05-1550

63. Li Y, Choi H, Zhou Z, Nolasco L, Pownall HJ, Voorberg J, et al. Covalent regulation of ULVWF string formation and elongation on endothelial cells under flow conditions. J Thromb Haemost. (2008) 6:113543. doi: 10.1111/j.1538-7836.2008.02991.x

64. Swami A, Kaur V. von Willebrand disease: a concise review and update for the practicing physician. Clin Appl Thromb Hemost. (2017) 23:900-10. doi: 10.1177/1076029616675969

65. Spiel Alexander O, Gilbert James C, Jilma B. Von Willebrand factor in cardiovascular disease. Circulation. (2008) 117:1449-59. doi: 10.1161/CIRCULATIONAHA.107.722827

66. Rivera J, Lozano ML, Navarro-Nunez L, Vicente V. Platelet receptors and signaling in the dynamics of thrombus formation. Haematologica. (2009) 94:700-11. doi: 10.3324/haematol.2008.003178

67. Frankel David S, Meigs James B, Massaro Joseph M, Wilson Peter WF, O'donnell Christopher J, D'agostino Ralph B, et al. Von Willebrand factor, type 2 diabetes mellitus, and risk of cardiovascular disease. Circulation. (2008) 118:2533-9. doi: 10.1161/CIRCULATIONAHA.108.792986

68. Van Loon JE, Kavousi M, Leebeek FW, Felix JF, Hofman A, Witteman JC, et al. von Willebrand factor plasma levels, genetic variations and coronary heart disease in an older population. J Thromb Haemost. (2012) 10:1262-9. doi: 10.1111/j.1538-7836.2012.04771.x

69. Takahashi M, Yamashita A, Moriguchi-Goto S, Marutsuka K, Sato $\mathrm{Y}$, Yamamoto $\mathrm{H}$, et al. Critical role of von Willebrand factor and platelet interaction in venous thromboembolism. Histol Histopathol. (2009) 24:1391-8. doi: 10.14670/HH-24.1391

70. Sadler JE. Biochemistry and genetics of von Willebrand factor. Annu Rev Biochem. (1998) 67:395-424. doi: 10.1146/annurev.biochem.67.1.395

71. De Gennes PG. Coil-stretch transition of dilute flexible polymers under ultrahigh velocity gradients. J Chem Phys. (1974) 60:5030-42. doi: $10.1063 / 1.1681018$

72. Smith DE, Babcock HP, Chu S. Single-polymer dynamics in steady shear flow. Science. (1999) 283:1724. doi: 10.1126/science.283.5408.1724

73. Ulrichts H, Vanhoorelbeke K, Girma JP, Lenting PJ, Vauterin S, Deckmyn H. The von Willebrand factor self-association is modulated by a multiple domain interaction. J Thromb Haemost. (2005) 3:552-61. doi: 10.1111/j.1538-7836.2005.01209.x

74. De Luca M, Facey DA, Favaloro EJ, Hertzberg MS, Whisstock JC, Mcnally $\mathrm{T}$, et al. Structure and function of the von Willebrand factor Al domain: analysis with monoclonal antibodies reveals distinct binding sites involved in recognition of the platelet membrane glycoprotein Ib-IX-V complex and ristocetin-dependent activation. Blood. (2000) 95:164.

75. Di Stasio E, De Cristofaro R. The effect of shear stress on protein conformation: physical forces operating on biochemical systems: the case of von Willebrand factor. Biophys Chem. (2010) 153:1-8. doi: $10.1016 /$ j.bpc. 2010.07 .002
76. Doyle PS, Ladoux B, Viovy J-L. Dynamics of a tethered polymer in shear flow. Phys Rev Lett. (2000) 84:4769-72. doi: 10.1103/PhysRevLett.84.4769

77. Alexander-Katz A, Schneider MF, Schneider SW, Wixforth A, Netz RR. Shear-flow-induced unfolding of polymeric globules. Phys Rev Lett. (2006) 97:138101. doi: 10.1103/PhysRevLett.97.138101

78. Springer TA. von Willebrand factor, Jedi knight of the bloodstream. Blood. (2014) 124:1412-25. doi: 10.1182/blood-2014-05-378638

79. Siedlecki CA, Lestini BJ, Kottke-Marchant KK, Eppell SJ, Wilson DL, Marchant RE. Shear-dependent changes in the three-dimensional structure of human von Willebrand factor. Blood. (1996) 88:2939-50.

80. Ruggeri ZM, Orje JN, Habermann R, Federici AB, Reininger AJ. Activationindependent platelet adhesion and aggregation under elevated shear stress. Blood. (2006) 108:1903-10. doi: 10.1182/blood-2006-04-011551

81. Zhang $\mathrm{X}$, Halvorsen $\mathrm{K}$, Zhang C-Z, Wong WP, Springer TA. Mechanoenzymatic cleavage of the ultralarge vascular protein von willebrand factor. Science. (2009) 324:1330. doi: 10.1126/science.1170905

82. Sing CE, Alexander-Katz A. Elongational flow induces the unfolding of von Willebrand factor at physiological flow rates. Biophys J. (2010) 98:L35-7. doi: 10.1016/j.bpj.2010.01.032

83. Fu H, Jiang Y, Yang D, Scheiflinger F, Wong WP, Springer TA. Flow-induced elongation of von Willebrand factor precedes tension-dependent activation. Nat Commun. (2017) 8:324. doi: 10.1038/s41467-017-00230-2

84. Ying J, Ling Y, Westfield LA, Sadler JE, Shao J-Y. Unfolding the A2 domain of von Willebrand factor with the optical trap. Biophys J. (2010) 98:1685-93. doi: 10.1016/j.bpj.2009.12.4324

85. Joly BS, Coppo P, Veyradier A. Thrombotic thrombocytopenic purpura. Blood. (2017) 129:2836-46. doi: 10.1182/blood-2016-10-709857

86. $\mathrm{Xu}$ AJ, Springer TA. Calcium stabilizes the von Willebrand factor A2 domain by promoting refolding. Proc Natl Acad Sci USA. (2012) 109:3742. doi: 10.1073/pnas.1121261109

87. Reininger AJ, Heijnen HFG, Schumann H, Specht HM, Schramm W, Ruggeri ZM. Mechanism of platelet adhesion to von Willebrand factor and microparticle formation under high shear stress. Blood. (2006) 107:3537-45. doi: 10.1182/blood-2005-02-0618

88. Ruggeri ZM, Mendolicchio GL. Interaction of von Willebrand factor with platelets and the vessel wall. Hamostaseologie. (2015) 35:211-24. doi: 10.5482/HAMO-14-12-0081

89. Ruggeri ZM. Platelet adhesion under flow. Microcirculation. (2009) 16:58-83. doi: 10.1080/10739680802651477

90. Berndt MC, Ward CM, Booth WJ, Castaldi PA, Mazurov AV, Andrews RK. Identification of aspartic acid 514 through glutamic acid 542 as a glycoprotein Ib-IX complex receptor recognition sequence in von Willebrand factor. Mechanism of modulation of von Willebrand factor by ristocetin and botrocetin. Biochemistry. (1992) 31:11144-51. doi: 10.1021/bi00160a027

91. Dong J-F, Berndt MC, Schade A, Mcintire LV, Andrews RK, López JA. Ristocetin-dependent, but not botrocetin-dependent, binding of von Willebrand factor to the platelet glycoprotein Ib-IX-V complex correlates with shear-dependent interactions. Blood. (2001) 97:162. doi: 10.1182/blood.V97.1.162

92. Mazzucato M, Spessotto P, Masotti A, De Appollonia L, Cozzi MR, Yoshioka A, et al. Identification of domains responsible for von Willebrand factor type VI collagen interaction mediating platelet adhesion under high flow. J Biol Chem. (1999) 274:3033-41. doi: 10.1074/jbc.274.5.3033

93. Bergmeier W, Piffath CL, Goerge T, Cifuni SM, Ruggeri ZM, Ware J, et al. The role of platelet adhesion receptor GPIbalpha far exceeds that of its main ligand, von Willebrand factor, in arterial thrombosis. Proc Natl Acad Sci USA. (2006) 103:16900-5. doi: 10.1073/pnas.0608207103

94. Clemetson KJ, Clemetson JM. Platelet GPIb-V-IX complex. Structure, function, physiology, and pathology. Semin Thromb Hemost. (1995) 21:130-6. doi: 10.1055/s-2007-1000387

95. Mcewan PA, Yang W, Carr KH, Mo X, Zheng X, Li R, et al. Quaternary organization of GPIb-IX complex and insights into Bernard-Soulier syndrome revealed by the structures of GPIb $\beta$ and a GPIb $\beta /$ GPIX chimera. Blood. (2011) 118:5292-301. doi: 10.1182/blood-2011-05-356253

96. Nakamura F, Pudas R, Heikkinen O, Permi P, Kilpelainen I, Munday $\mathrm{AD}$, et al. The structure of the GPIb-filamin A complex. Blood. (2006) 107:1925-32. doi: 10.1182/blood-2005-10-3964 
97. Christiaens L, Macchi L, Duplantier C, Allal J, Brizard A, Barraine R, et al. Platelet polymorphism and coronary artery disease. Arch Mal Coeur Vaiss. (2002) 95:173-8.

98. Meisel CA, López J, Stangl K. Role of platelet glycoprotein polymorphisms in cardiovascular diseases. Naunyn Schmiedebergs Arch Pharmacol. (2004) 369:38-54. doi: 10.1007/s00210-003-0828-y

99. Huizinga EG, Tsuji S, Romijn RA, Schiphorst ME, De Groot PG, Sixma JJ, et al. Structures of glycoprotein Ibalpha and its complex with von Willebrand factor A1 domain. Science. (2002) 297:1176-9. doi: 10.1126/science.107355

100. Alsallaq R, Zhou HX. Electrostatic rate enhancement and transient complex of protein-protein association. Proteins. (2008) 71:320-35. doi: $10.1002 /$ prot.21679

101. Yago T, Lou J, Wu T, Yang J, Miner JJ, Coburn L, et al. Platelet glycoprotein Ibalpha forms catch bonds with human WT vWF but not with type 2B von Willebrand disease vWF. J Clin Invest. (2008) 118:3195-207. doi: 10.1172/JCI35754

102. Ju L, Dong JF, Cruz MA, Zhu C. The N-terminal flanking region of the Al domain regulates the force-dependent binding of von Willebrand factor to platelet glycoprotein Ibalpha. J Biol Chem. (2013) 288:32289-301. doi: 10.1074/jbc.M113.504001

103. Kim J, Zhang C-Z, Zhang X, Springer TA. A mechanically stabilized receptor-ligand flex-bond important in the vasculature. Nature. (2010) 466:992. doi: 10.1038/nature09295

104. Zhang W, Deng W, Zhou L, Xu Y, Yang W, Liang X, et al. Identification of a juxtamembrane mechanosensitive domain in the platelet mechanosensor glycoprotein Ib-IX complex. Blood. (2015) 125:562-9. doi: 10.1182/blood-2014-07-589507

105. Shen Y, Dong J, Romo GM, Arceneaux W, Aprico A, Gardiner EE, et al. Functional analysis of the C-terminal flanking sequence of platelet glycoprotein Ib $\alpha$ using canine-human chimeras. Blood. (2002) 1:145-50. doi: 10.1182/blood.V99.1.145

106. Shen Y, Cranmer SL, Aprico A, Whisstock JC, Jackson SP, Berndt MC, et al. Leucine-rich repeats 2-4 (Leu60-Glu128) of platelet glycoprotein Ibalpha regulate shear-dependent cell adhesion to von Willebrand factor. J Biol Chem. (2006) 281:26419-23. doi: 10.1074/jbc.M604296200

107. Ju L, Lou J, Chen Y, Li Z, Zhu C. Force-induced unfolding of leucine-rich repeats of glycoprotein ib $\alpha$ strengthens ligand interaction. Biophys J. (2015) 109:1781-4. doi: 10.1016/j.bpj.2015.08.050

108. Ju L, Chen Y, Xue L, Du X, Zhu C. Cooperative unfolding of distinctive mechanoreceptor domains transduces force into signals. Elife. (2016) 5:e15447. doi: 10.7554/eLife.15447

109. Nesbitt WS, Kulkarni S, Giuliano S, Goncalves I, Dopheide SM, Yap CL, et al. Distinct glycoprotein Ib/V/IX and integrin alpha IIbbeta 3-dependent calcium signals cooperatively regulate platelet adhesion under flow. J Biol Chem. (2002) 277:2965-72. doi: 10.1074/jbc.M1 10070200

110. Dai K, Bodnar R, Berndt MC, Du X. A critical role for 14-3-3zeta protein in regulating the VWF binding function of platelet glycoprotein Ib-IX and its therapeutic implications. Blood. (2005) 106:1975-81. doi: 10.1182/blood-2005-01-0440

111. Chen Y, Ju LA, Zhou F, Liao J, Xue L, Su QP, et al. An integrin $\alpha \operatorname{IIb} \beta 3$ intermediate affinity state mediates biomechanical platelet aggregation. Nat Mater. (2019) 18:760-9. doi: 10.1038/s41563-019-0323-6

112. Jackson SP. The growing complexity of platelet aggregation. Blood. (2007) 109:5087. doi: 10.1182/blood-2006-12-027698

113. Slager CJ, Wentzel JJ, Gijsen FJH, Thury A, Van Der Wal AC, Schaar JA, et al. The role of shear stress in the destabilization of vulnerable plaques and related therapeutic implications. Nat Clin Pract Cardiovasc Med. (2005) 2:456. doi: 10.1038/ncpcardio0298

114. Young DF, Tsai FY. Flow characteristics in models of arterial stenoses. II. Unsteady flow. J Biomech. (1973) 6:547-59. doi: 10.1016/0021-9290(73)90012-2

115. Chiu J-J, Chien S. Effects of disturbed flow on vascular endothelium: pathophysiological basis and clinical perspectives. Physiol Rev. (2011) 91:327-87. doi: 10.1152/physrev.00047.2009

116. Ruggeri ZM. Platelets in atherothrombosis. Nat Med. (2002) 8:1227-34. doi: 10.1038/nm1102-1227

117. Nesbitt WS, Westein E, Tovar-Lopez FJ, Tolouei E, Mitchell A, Fu $\mathrm{J}$, et al. A shear gradient-dependent platelet aggregation mechanism drives thrombus formation. Nat Med. (2009) 15:665-73. doi: 10.1038/ nm.1955

118. Sheriff J, Bluestein D, Girdhar G, Jesty J. High-shear stress sensitizes platelets to subsequent low-shear conditions. Ann Biomed Eng. (2010) 38:1442-50. doi: 10.1007/s10439-010-9936-2

119. Rahman SM, Eichinger CD, Hlady V. Effects of upstream shear forces on priming of platelets for downstream adhesion and activation. Acta Biomater. (2018) 73:228-35. doi: 10.1016/j.actbio.2018.04.002

120. Westein E, Van Der Meer AD, Kuijpers MJ, Frimat JP, Van Den Berg A, Heemskerk JW. Atherosclerotic geometries exacerbate pathological thrombus formation poststenosis in a von Willebrand factor-dependent manner. Proc Natl Acad Sci USA. (2013) 110:1357-62. doi: 10.1073/pnas.1209905110

121. Mustard JF, Murphy EA, Rowsell HC, Downie HG. Factors influencing thrombus formation in vivo. Am J Med. (1962) 33:621-47. doi: 10.1016/0002-9343(62)90243-7

122. Wentzel JJ, Chatzizisis YS, Gijsen FJ, Giannoglou GD, Feldman CL, Stone $\mathrm{PH}$. Endothelial shear stress in the evolution of coronary atherosclerotic plaque and vascular remodelling: current understanding and remaining questions. Cardiovasc Res. (2012) 96:234-43. doi: 10.1093/cvr/cvs217

123. Ha H, Lee S-J. Hemodynamic features and platelet aggregation in a stenosed microchannel. Microvasc Res. (2013) 90:96-105. doi: 10.1016/j.mvr.2013.08.008

124. Rinder CS, Student LA, Bonan JL, Rinder HM, Smith BR. Aspirin does not inhibit adenosine diphosphate-induced platelet alpha-granule release. Blood. (1993) 82:505-12.

125. Barstad RM, Orvim U, Hamers MJ, Tjonnfjord GE, Brosstad FR, Sakariassen KS. Reduced effect of aspirin on thrombus formation at high shear and disturbed laminar blood flow. Thromb Haemost. (1996) 75:827-32. doi: 10.1055/s-0038-1650374

126. Maalej N, Folts John D. Increased shear stress overcomes the antithrombotic platelet inhibitory effect of aspirin in stenosed dog coronary arteries. Circulation. (1996) 93:1201-5. doi: 10.1161/01.CIR.93.6.1201

127. Weiss HJ, Turitto VT. Prostacyclin (prostaglandin I2, PGI2) inhibits platelet adhesion and thrombus formation on subendothelium. Blood. (1979) 53:244.

128. Borgdorff P, Tangelder GJ, Paulus WJ. Cyclooxygenase-2 inhibitors enhance shear stress-induced platelet aggregation. J Am Coll Cardiol. (2006) 48:817-23. doi: 10.1016/j.jacc.2006.03.053

129. Kageyama S, Yamamoto H, Nagano M, Arisaka H, Kayahara T, Yoshimoto R. Anti-thrombotic effects and bleeding risk of AJvW-2, a monoclonal antibody against human von Willebrand factor. Br J Pharmacol. (1997) 122:165-71. doi: 10.1038/sj.bjp.0701354

130. Eto K, Isshiki T, Yamamoto H, Takeshita S, Ochiai M, Yokoyama N, et al. AJvW-2, an anti-vWF monoclonal antibody, inhibits enhanced platelet aggregation induced by high shear stress in platelet-rich plasma from patients with acute coronary syndromes. Arterioscler Thromb Vasc Biol. (1999) 19:877-82. doi: 10.1161/01.ATV.19.4.877

131. Kageyama S, Yamamoto H, Yoshimoto R. Anti-human von Willebrand factor monoclonal antibody AJvW-2 prevents thrombus deposition and neointima formation after balloon injury in guinea pigs. Arterioscler Thromb Vasc Biol. (2000) 20:2303-8. doi: 10.1161/01.ATV.20.10.2303

132. Kageyama S, Yamamoto H, Nakazawa H, Matsushita J, Kouyama T, Gonsho A, et al. Pharmacokinetics and pharmacodynamics of AJW200, a humanized monoclonal antibody to von Willebrand factor, in monkeys. Arterioscler Thromb Vasc Biol. (2002) 22:187-92. doi: 10.1161/hq0102.101520

133. Kageyama S, Matsushita J, Yamamoto H. Effect of a humanized monoclonal antibody to von Willebrand factor in a canine model of coronary arterial thrombosis. Eur J Pharmacol. (2002) 443:143-9. doi: 10.1016/S0014-2999(02)01590-X

134. Machin S, Clarke C, Ikemura O, Kageyama S, Mackie IJ, Talbot JA, et al. A humanised monoclonal antibody against VWF A1 domain inhibits VWF: RiCof activity and platelet adhesion in human volunteers. J Thromb Haemost. (2003).

135. Diener JL, Daniel Lagasse HA, Duerschmied D, Merhi Y, Tanguay JF, Hutabarat R, et al. Inhibition of von Willebrand factor-mediated platelet activation and thrombosis by the anti-von Willebrand factor A1-domain aptamer ARC1779. J Thromb Haemost. (2009) 7:1155-62. doi: $10.1111 / \mathrm{j} .1538-7836.2009 .03459 . \mathrm{x}$ 
136. (2019). FDA Approved Caplacizumab-yhdp. Available online at: https://www. fda.gov (accessed April 1, 2019).

137. Jilma-Stohlawetz P, Gilbert JC, Gorczyca ME, Knöbl P, Jilma B. A dose ranging phase I/II trial of the von Willebrand factor inhibiting aptamer ARC1779 in patients with congenital thrombotic thrombo - cytopenic purpura. Thromb Haemost. (2011) 106:391-7. doi: 10.1160/TH11-02-0069

138. Markus HS, Mccollum C, Imray C, Goulder MA, Gilbert J, King A. The von Willebrand inhibitor ARC1779 reduces cerebral embolization after carotid endarterectomy: a randomized trial. Stroke. (2011) 42:2149-53. doi: 10.1161/STROKEAHA.111.616649

139. Siller-Matula JM, Merhi Y, Tanguay JF, Duerschmied D, Wagner DD, Mcginness KE, et al. ARC15105 is a potent antagonist of von Willebrand factor mediated platelet activation and adhesion. Arterioscler Thromb Vasc Biol. (2012) 32:902-9. doi: 10.1161/ATVBAHA.111.237529

140. Bartunek JB, Vercruysse K, Duby C, Wijns W, Heyndrickx G, Holz J-B. Abstract 15084: safety and efficacy of anti-von Willebrand factor nanobody ${ }^{\circledR}$ ALX-0081 in stable angina patients undergoing percutaneous coronary intervention. Circulation. (2010) 122:A15084.

141. Loon JEV, Jaegere PPTD, Vliet HHDMV, Maat MPMD, De Groot PG, Simoons ML, et al. The in vitro effect of the new antithrombotic drug candidate ALX-0081 on blood samples of patients undergoing percutaneous coronary intervention. Thromb Haemost. (2011) 106:165-71. doi: 10.1160/TH10-12-0804

142. Callewaert F, Roodt J, Ulrichts H, Stohr T, Van Rensburg WJ, Lamprecht S, et al. Evaluation of efficacy and safety of the anti-VWF Nanobody ALX-0681 in a preclinical baboon model of acquired thrombotic thrombocytopenic purpura. Blood. (2012) 120:3603-10. doi: 10.1182/blood-2012-04-420943

143. Peyvandi F, Scully M, Kremer Hovinga JA, Cataland S, Knobl P, Wu H, et al. Caplacizumab for acquired thrombotic thrombocytopenic purpura. $N$ Engl J Med. (2016) 374:511-22. doi: 10.1056/NEJMoa1505533

144. Scully M, Cataland SR, Peyvandi F, Coppo P, Knöbl P, Kremer Hovinga JA, et al. Results of the randomized, double-blind, placebo-controlled, phase 3 hercules study of caplacizumab in patients with acquired thrombotic thrombocytopenic purpura. Blood. (2017) 130:LBA-1.

145. Gorog DA, Douglas H, Ahmed N, Lefroy DC, Davies GJ. Coronary angioplasty enhances platelet reactivity through von Willebrand factor release. Heart. (2003) 89:329-30. doi: 10.1136/heart.89.3.329

146. Kremer Hovinga JA, Meyer SC. Current management of thrombotic thrombocytopenic purpura. Curr Opin Hematol. (2008) 15:445-50. doi: 10.1097/MOH.0b013e328309ec62

147. Korin N, Kanapathipillai M, Matthews BD, Crescente M, Brill A, Mammoto $\mathrm{T}$, et al. Shear-activated nanotherapeutics for drug targeting to obstructed blood vessels. Science. (2012) 337:738-42. doi: 10.1126/science.1217815

148. Marosfoi MG, Korin N, Gounis MJ, Uzun O, Vedantham S, Langan ET, et al. Shear-activated nanoparticle aggregates combined with temporary endovascular bypass to treat large vessel occlusion. Stroke. (2015) 46:3507-13. doi: 10.1161/STROKEAHA.115.011063

149. Holme MN, Fedotenko IA, Abegg D, Althaus J, Babel L, Favarger F, et al. Shear-stress sensitive lenticular vesicles for targeted drug delivery. Nat Nanotechnol. (2012) 7:536-43. doi: 10.1038/nnano.2012.84

150. Molloy CP, Yao Y, Kammoun H, Bonnard T, Hoefer T, Alt K, et al. Shear-sensitive nanocapsule drug release for site-specific inhibition of occlusive thrombus formation. J Thromb Haemost. (2017) 15:972-82. doi: $10.1111 /$ jth. 13666

151. Westein E, Flierl U, Hagemeyer C, Peter K. Destination known: targeted drug delivery in atherosclerosis and thrombosis. Drug Dev Res. (2013) 74. doi: 10.1002/ddr.21103

152. Korin N, Gounis MJ, Wakhloo AK, Ingber DE. Targeted drug delivery to flow-obstructed blood vessels using mechanically activated nanotherapeuticsnanotherapeutics for flow-obstructed blood vesselsnanotherapeutics for flow-obstructed blood vessels. JAMA Neurol. (2015) 72:119-22. doi: 10.1001/jamaneurol.2014.2886

153. Xia Y, Shi CY, Xiong W, Hou XL, Fang JG, Wang WQ. Shear stress-sensitive carriers for localized drug delivery. Curr Pharm Des. (2016) 22:5855-67. doi: 10.2174/1381612822666160628 081419

154. Epshtein M, Korin N. Shear targeted drug delivery to stenotic blood vessels. J Biomech. (2017) 50:217-21. doi: 10.1016/j.jbiomech.2016.11.015
155. Metselaar JM, Storm G. Liposomes in the treatment of inflammatory disorders. Expert Opin Drug Deliv. (2005) 2:465-76. doi: 10.1517/17425247.2.3.465

156. Ding BS, Dziubla T, Shuvaev VV, Muro S, Muzykantov VR. Advanced drug delivery systems that target the vascular endothelium. Mol Interv. (2006) 6:98-112. doi: $10.1124 / \mathrm{mi} .6 .2 .7$

157. Hua S, Wu SY. The use of lipid-based nanocarriers for targeted pain therapies. Front Pharmacol. (2013) 4:143. doi: 10.3389/fphar.2013.00143

158. Monteiro N, Martins A, Reis RL, Neves NM. Liposomes in tissue engineering and regenerative medicine. $J$ R Soc Interface. (2014) 11:20140459. doi: 10.1098/rsif.2014.0459

159. Sackmann E. Membrane bending energy concept of vesicle- and cell-shapes and shape-transitions. FEBS Lett. (1994) 346:3-16. doi: 10.1016/0014-5793(94)00484-6

160. Bernard A-L, Guedeau-Boudeville M-A, Marchi-Artzner V, GulikKrzywicki T, Di Meglio J-M, Jullien L. Shear-induced permeation and fusion of lipid vesicles. J Colloid Interface Sci. (2005) 287:298-306. doi: 10.1016/j.jcis.2004.12.019

161. Guo X, Wu Z, Guo Z. New method for site-specific modification of liposomes with proteins using sortase A-mediated transpeptidation. Bioconjug Chem. (2012) 23:650-5. doi: 10.1021/bc200694t

162. Hagemeyer CE, Alt K, Johnston APR, Such GK, Ta HT, Leung MKM, et al. Particle generation, functionalization and sortase A-mediated modification with targeting of single-chain antibodies for diagnostic and therapeutic use. Nat Protoc. (2014) 10:90. doi: 10.1038/nprot.2014.177

163. Wöll S, Bachran C, Schiller S, Schröder M, Conrad L, Swee LK, et al. Sortaggable liposomes: evaluation of reaction conditions for single-domain antibody conjugation by Sortase-A and targeting of CD11b + myeloid cells. Eur J Pharm Biopharm. (2018) 133:138-50. doi: 10.1016/j.ejpb.2018.09.017

164. Bajaj SP, Joist JH. New insights into how blood clots: implications for the use of APTT and PT as coagulation screening tests and in monitoring of anticoagulant therapy. Semin Thromb Hemost. (1999) 25:407-18. doi: 10.1055/s-2007-994943

165. Chee YL, Greaves M. Role of coagulation testing in predicting bleeding risk. Hematol J. (2003) 4:373-8. doi: 10.1038/sj.thj.6200306

166. Ganter MT, Hofer CK. Coagulation monitoring: current techniques and clinical use of viscoelastic point-of-care coagulation devices. Anesth Analg. (2008) 106:1366-75. doi: 10.1213/ane.0b013e318168b367

167. Para AN, Ku DN. A low-volume, single pass $<$ em $>$ in-vitro $</ \mathrm{em}>$ system of high shear thrombosis in a stenosis. Thromb Res. (2013) 131:418-24. doi: 10.1016/j.thromres.2013.02.018

168. Jain A, Graveline A, Waterhouse A, Vernet A, Flaumenhaft R, Ingber DE. A shear gradient-activated microfluidic device for automated monitoring of whole blood haemostasis and platelet function. Nat Commun. (2016) 7:10176. doi: 10.1038/ncomms10176

169. Jin-Wook Y, Elizabeth C, Samir M. Factors that control the circulation time of nanoparticles in blood: challenges, solutions and future prospects. Curr Pharm Des. (2010) 16:2298-307. doi: 10.2174/138161210791920496

170. Patra JK, Das G, Fraceto LF, Campos EVR, Rodriguez-Torres MDP, Acosta-Torres LS, et al. Nano based drug delivery systems: recent developments and future prospects. J Nanobiotechnology. (2018) $16: 71$. doi: 10.1186/s12951-018-0392-8

171. Paliwal R, Babu RJ, Palakurthi S. Nanomedicine scale-up technologies: feasibilities and challenges. AAPS PharmSciTech. (2014) 15:1527-34. doi: 10.1208/s12249-014-0177-9

172. Wilczewska AZ, Niemirowicz K, Markiewicz KH, Car H. Nanoparticles as drug delivery systems. Pharmacol Rep. (2012) 64:1020-37. doi: 10.1016/S1734-1140(12)70901-5

173. Bhatt DL, Topol EJ. Scientific and therapeutic advances in antiplatelet therapy. Nat Rev Drug Discov. (2003) 2:15-28. doi: 10.1038/nrd985

174. Antithrombotic Trialists' Collaboration. Collaborative meta-analysis of randomised trials of antiplatelet therapy for prevention of death, myocardial infarction, and stroke in high risk patients. BMJ. (2002) 324:71-86. doi: $10.1136 / \mathrm{bmj} .324 .7329 .71$

175. Sands AT. The master mammal. Nat Biotechnol. (2003) 21:31-2. doi: 10.1038/nbt0103-31

176. Diaz JA, Obi AT, Myers DD Jr, Wrobleski SK, Henke PK, Mackman N, et al. Critical review of mouse models of venous thrombosis. Arterioscler 
Thromb Vasc Biol. (2012) 32:556-62. doi: 10.1161/ATVBAHA.111. 244608

177. Vogel V. Mechanotransduction involving multimodular proteins: converting force into biochemical signals. Annu Rev Biophys Biomol Struct. (2006) 35:459-88. doi: 10.1146/annurev.biophys.35.040405.102013

178. Chen Y, Ju L, Rushdi M, Ge C, Zhu C. Receptor-mediated cell mechanosensing. Mol Biol Cell. (2017) 28:3134-55. doi: 10.1091/mbc.e17-04-0228

179. Perkins WR, Vaughan DE, Plavin SR, Daley WL, Rauch J, Lee L, et al. Streptokinase entrapment in interdigitation-fusion liposomes improves thrombolysis in an experimental rabbit model. Thromb Haemost. (1997) 77:1174-8. doi: 10.1055/s-0038-1656133

180. Leach JK, O'rear EA, Patterson E, Miao Y, Johnson AE. Accelerated thrombolysis in a rabbit model of carotid artery thrombosis with liposome-encapsulated and microencapsulated streptokinase. Thromb Haemost. (2003) 90:64-70. doi: 10.1055/s-0037-16 13600
181. Andresen TL, Jensen SS, Jorgensen K. Advanced strategies in liposomal cancer therapy: problems and prospects of active and tumor specific drug release. Prog Lipid Res. (2005) 44:68-97. doi: 10.1016/j.plipres.2004.12.001

182. Arayne MS, Sultana N, Qureshi F. Review: nanoparticles in delivery of cardiovascular drugs. Pak J Pharm Sci. (2007) 20:340-8.

Conflict of Interest: The authors declare that the research was conducted in the absence of any commercial or financial relationships that could be construed as a potential conflict of interest.

Copyright (๑) 2019 Rana, Westein, Niego and Hagemeyer. This is an open-access article distributed under the terms of the Creative Commons Attribution License (CC $B Y)$. The use, distribution or reproduction in other forums is permitted, provided the original author(s) and the copyright owner(s) are credited and that the original publication in this journal is cited, in accordance with accepted academic practice. No use, distribution or reproduction is permitted which does not comply with these terms. 